\title{
Beclin-1-mediated activation of autophagy improves proximal and distal urea cycle disorders
}

\author{
Leandro R Soria $^{1}$ (D), Sonam Gurung ${ }^{2}$, Giulia De Sabbata ${ }^{3}$, Dany P Perocheau ${ }^{2}$ (D), Angela De Angelis ${ }^{1}$, \\ Gemma Bruno ${ }^{1}$, Elena Polishchuk ${ }^{1}$, Debora Paris ${ }^{4}$, Paola Cuomo ${ }^{4}$, Andrea Motta ${ }^{4}$, Michael Orford ${ }^{2}$, \\ Youssef Khalil $^{2}$ (D), Simon Eaton ${ }^{2}$, Philippa B Mills², Simon N Waddington ${ }^{2,5}$, Carmine Settembre ${ }^{1}$ (iD, \\ Andrés F Muro ${ }^{3}$ (D), Julien Baruteau ${ }^{2,6}$ (D) \& Nicola Brunetti-Pierri ${ }^{1,7, *}$ (D)
}

\begin{abstract}
Urea cycle disorders (UCD) are inherited defects in clearance of waste nitrogen with high morbidity and mortality. Novel and more effective therapies for UCD are needed. Studies in mice with constitutive activation of autophagy unravelled Beclin-1 as druggable candidate for therapy of hyperammonemia. Next, we investigated efficacy of cell-penetrating autophagy-inducing Tat-Beclin-1 (TB-1) peptide for therapy of the two most common UCD, namely ornithine transcarbamylase (OTC) and argininosuccinate lyase (ASL) deficiencies. TB-1 reduced urinary orotic acid and improved survival under protein-rich diet in spf-ash mice, a model of OTC deficiency (proximal UCD). In As/ ${ }^{\text {Neo/Neo }}$ mice, a model of ASL deficiency (distal UCD), TB-1 increased ureagenesis, reduced argininosuccinate, and improved survival. Moreover, it alleviated hepatocellular injury and decreased both cytoplasmic and nuclear glycogen accumulation in As/ ${ }^{\text {Neo/Neo }}$ mice. In conclusion, Beclin-1dependent activation of autophagy improved biochemical and clinical phenotypes of proximal and distal defects of the urea cycle.
\end{abstract}

Keywords argininosuccinic aciduria; autophagy; OTC deficiency; Tat-Beclin-1 peptide; urea cycle disorders

Subject Categories Autophagy \& Cell Death; Genetics, Gene Therapy \& Cenetic Disease

DOI 10.15252/emmm.202013158| Received 22 July 2020 | Revised 23

November 2020 | Accepted 25 November 2020

EMBO Mol Med (2020) e13158

\section{Introduction}

Autophagy is highly active in liver. Proteins, glycogen and lipid droplets are degraded by autophagy in liver cells to release amino acids, glucose and free fatty acids that can be reused for synthesis of new proteins and macromolecules, or can enter the tricarboxylic acid (TCA) cycle to generate ATP (Kaur \& Debnath, 2015). Liver autophagy was recently found to support ammonia detoxification by furnishing the urea cycle with intermediates and energy that increase urea cycle flux under conditions of excessive ammonia (Soria et al, 2018). Liver-specific deficiency of autophagy impaired ammonia detoxification whereas its enhancement resulted in increased urea synthesis and protection against hyperammonemia (Soria et al, 2018). Therefore, drugs enhancing autophagy have potential for treatment of urea cycle disorders (UCD) (Soria \& Brunetti-Pierri, 2018, 2019). In a previous study (Soria et al, 2018), we showed that rapamycin reduces orotic acid in spf-ash mice, a mouse model of the ornithine transcarbamylase (OTC) deficiency that carries a single nucleotide mutation in the fourth exon of the Otc gene resulting in a splicing defect and $10 \%$ of residual enzyme activity (Hodges \& Rosenberg, 1989). Although it has been efficiently used to promote autophagy, rapamycin does not completely inhibit its target, the mechanistic target of rapamycin kinase complex 1 (mTORC1), and affects several biological processes besides autophagy (Li et al, 2014). Therefore, drugs targeting autophagy more specifically are attractive because they are expected to have less side effects. Tat-Beclin-1 (TB-1) is an engineered cellpermeable peptide that potently and specifically induces autophagy (Shoji-Kawata et al, 2013). TB-1 is formed by the HIV-1 Tat protein transduction domain attached via a diglycine linker to a peptide derived from Beclin-1 (Becn1), a key component of the autophagy induction machinery (Shoji-Kawata et al, 2013). In summary, TB-1 is an attractive therapeutic candidate for its specificity and at least in mice, it has shown great potential for treatment of various diseases, including several types of cancer, infections, cardiac dysfunction, skeletal disorders and axonal injuries (Cinque et al, 2015; He et al, 2016; Pietrocola et al, 2016; Bartolomeo et al, 2017;

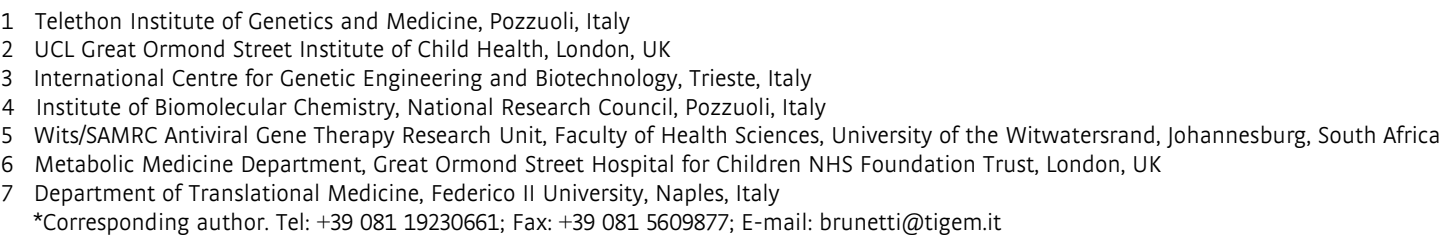


Song et al, 2018; Sun et al, 2018; Vega-Rubin-de-Celis et al, 2018). In the present study, we investigated the therapeutic potential of TB-1 for treatment of UCD.

\section{Results}

\section{Constitutional hyperactivation of Beclin-1 enhances ammonia detoxification}

Beclin-1 is a central player in autophagy and regulates autophagosome formation and maturation (Liang et al, 2008). To investigate Becn1 functions in vivo, a knock-in mouse model carrying a Becn 1 mutation $\left(B e c n 1^{F 121 A}\right.$ ) resulting in constitutively active autophagy has been recently generated (Rocchi et al, 2017). In these mice, Phe121 is mutated into alanine resulting in disruption of the BECN1-BCL2 binding and constitutive activation of BECN1 and autophagy in multiple tissues, including liver (Rocchi et al, 2017; Fernandez et al, 2018; Yamamoto et al, 2018). In these mice, we investigated ammonia detoxification by measurements of blood ammonia levels during acute hyperammonemia induced by an ammonia challenge. Despite no changes in blood ammonia at baseline, Becn $1^{F 121 A}$ mice showed $32 \%$ reduction in blood ammonia at 30 min after intraperitoneal (i.p.) injection of ammonium chloride compared to age-matched wild-type (WT) mice (Fig 1A). Accordingly, Becn $1^{F 121 A}$ mice showed enhanced ureagenesis compared to WT controls, as shown by increased blood levels of ${ }^{15} \mathrm{~N}$-labelled urea from ${ }^{15} \mathrm{~N}$-ammonium chloride (Fig EV1A). Improved ammonia clearance was not dependent on increased expression of urea cycle enzymes in Becn $1^{F 121 A}$ mice that showed similar enzyme levels by Western blotting compared to WT controls (Fig EV1B and C). Therefore, consistent with previous findings (Soria et al, 2018), gain-of-function mutation of the autophagy activator Becn 1 protects against acute hyperammonemia in vivo, suggesting that Beclin-1 is a druggable candidate for therapy of hyperammonemia.

\section{Tat-Beclin-1 improves the phenotype of OTC-deficient mice}

To investigate the therapeutic efficacy of Becn1-mediated induction of autophagy in mouse models of UCD, we injected TB-1 i.p. in spfash mice (Hodges \& Rosenberg, 1989), a model of OTC deficiency, the most common UCD. Body weights were unaffected by TB-1 (Fig EV2A). Although not normalized, in spf-ash mice the levels of the biochemical hallmark of OTC deficiency, urinary orotic acid, were significantly reduced by TB-1 (Fig 1B). Consistent with its autophagy enhancer activity, TB-1 increased the hepatic autophagic flux, as showed by reduced protein levels of the autophagosome marker LC3-II, and the two main autophagy cargo receptors, namely p62 and NBR1 (Fig 1C and D). Notably, OTC residual enzyme activity was unaffected by TB-1 (Fig EV2B), thus excluding reduction of urinary orotic acid as a consequence of increased residual OTC activity induced by TB-1. To further investigate the efficacy of TB-1mediated increased liver autophagy for therapy of OTC deficiency, spf-ash mice were fed for 10 days with a high protein diet and were either treated with TB-1 or left untreated. Consistent with previous reports (Yang et al, 2016; Kurtz et al, 2019), spf-ash mice showed marked mortality under high protein diet compared to control WT mice (Fig 1E). An approximately $30 \%$ weight loss was observed in all spf-ash mice fed with the high protein diet, independently of TB1 treatment (Fig EV2C). Although it did not significantly improved survival as single treatment, when combined with an ammonia scavenger drug (Na-benzoate) and L-arginine (L-Arg), TB-1 increased survival whereas ammonia scavengers and L-Arg did not affect survival of spf-ash mice under high protein diet (Fig 1E). Consistent with the increased survival, blood ammonia levels measured after 4 days with high protein diet (a time-point prior to mortality) were significantly lower in spf-ash mice treated with the combination of TB-1 and Na-benzoate and L-Arg compared to untreated spf-ash mice (Fig 1F). TB-1 alone decreased slightly but not significantly blood ammonia whereas Na-benzoate and L-Arg significantly reduced blood ammonia levels, consistent with the human data (Enns et al, 2007; Fig 1F). Notably, Na-benzoate and L-Arg treatment did not affect the levels of urinary orotic acid increased by the high protein diet whereas TB-1 either alone or in combination with Na-benzoate and L-Arg efficiently blunted the increase in urinary orotic acid induced by the high protein diet (Fig EV2D). Taken together, these results support the therapeutic potential of activation of liver autophagy by TB-1 in combination with conventional treatments, such as ammonia scavenger drugs and L-Arg (Enns et al, 2007; Haberle et al, 2019), for treatment of OTC deficiency, the most common UCD.

\section{Tat-Beclin-1 enhances ureagenesis and corrects metabolic abnormalities of argininosuccinic aciduria}

To investigate the efficacy of autophagy enhancement for therapy of argininosuccinic aciduria (ASA), the second most frequent UCD (Baruteau et al, 2019a), we investigated TB-1 treatment in the hypomorphic murine model of argininosuccinate lyase (ASL) deficiency $\left(A s l^{\mathrm{Neo} / \mathrm{Neo}}\right)$ that expresses approximately $16 \%$ of residual enzyme activity and recapitulates the main biochemical and clinical abnormalities of ASA patients (Erez et al, 2011; Nagamani et al, 2012; Baruteau et al, 2018; Burrage et al, 2020). Besides impaired urea synthesis and ammonia detoxification, systemic manifestations of ASA, such as reduced body weight, increased blood pressure, and reduced survival are also associated with nitric oxide (NO)-deficiency (Erez et al, 2011; Nagamani et al, 2012; Baruteau et al, 2018; Kho et al, 2018). Asl $l^{\mathrm{Neo} / \mathrm{Neo}}$ mice treated with TB-1 but without any additional treatment showed increased survival compared to vehicle-treated controls that started dying by 10 days of age (Fig $2 \mathrm{~A}$ ). Weight gain was unaffected by TB-1 (Fig EV3A). Consistent with our previous work (Soria et al, 2018), TB-1-mediated activation of autophagy in $A s l^{\text {Neo/Neo mice was associated with increased incorpo- }}$ ration of ${ }^{15} \mathrm{~N}$ into urea $(+88 \%, P<0.05)$ indicating enhanced ureagenesis (Fig 2B). Consistent with the increased ureagenesis, blood ammonia levels were lowered by TB-1 in $A s l^{\mathrm{Neo} / \mathrm{Neo}}$ mice (Fig EV3B). As expected, autophagic flux was enhanced in livers of $A s l^{\mathrm{Neo} / \mathrm{Neo}}$ mice injected with TB-1, as shown by reduced LC3-II and decreased autophagy substrates (p62 and NBR1) in livers (Fig 2C and D), whereas residual ASL enzyme activity was unaffected (Fig EV3C). Argininosuccinic acid levels were reduced in dried blood spots (Fig 2E) in TB-1-treated Asl ${ }^{\mathrm{Neo} / \mathrm{Neo}}$ mice. Consistent with this reduction, hepatic content of ${ }^{15} \mathrm{~N}$-labelled argininosuccinic acid was also reduced in mice treated with TB-1 (Fig 2F). Metabolomic analysis by ${ }^{1} \mathrm{H}$-NMR spectroscopy (Soria et al, 2018) showed that the whole-liver metabolome of vehicle-treated $A s l^{\mathrm{Neo} / \mathrm{NeO}}$ mice was 

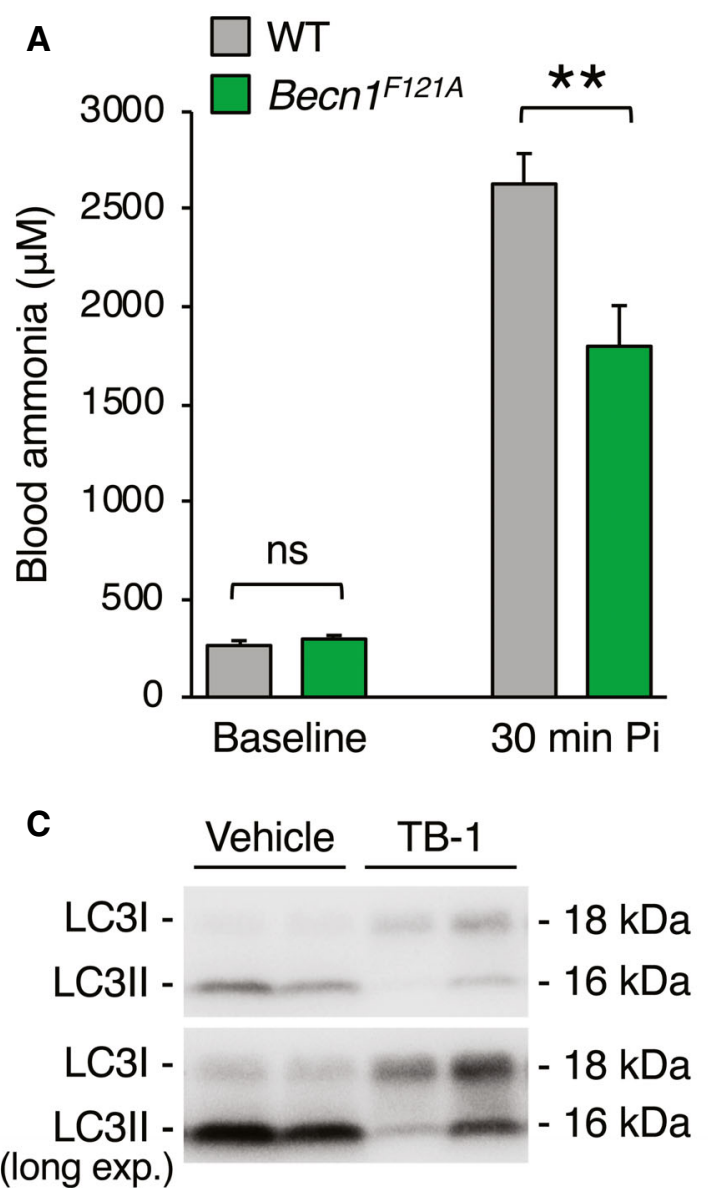

$\beta$-actin - $\square-42 \mathrm{kDa}$

NBR1 - - - - - $135 \mathrm{kDa}$
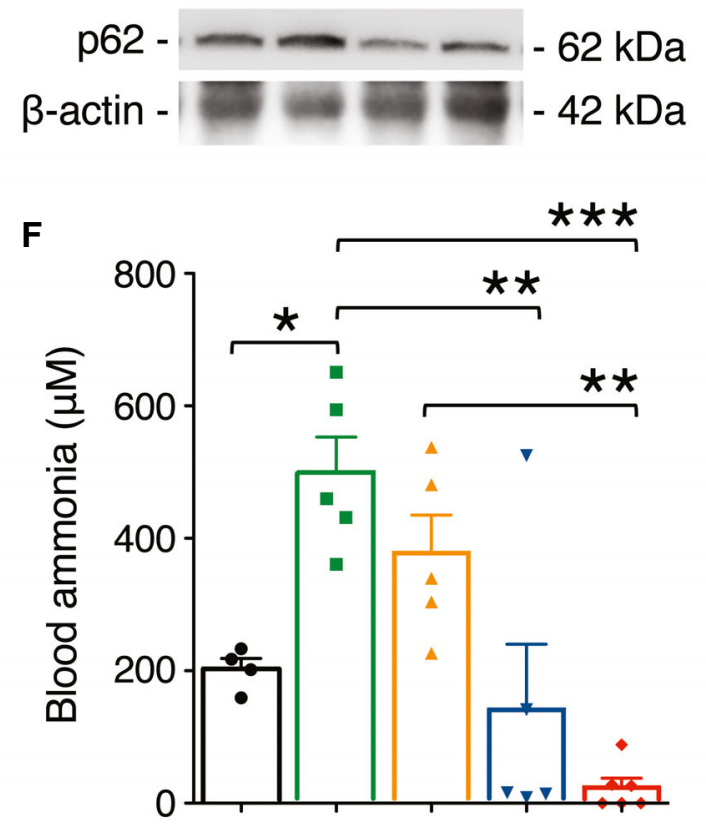

Figure 1.

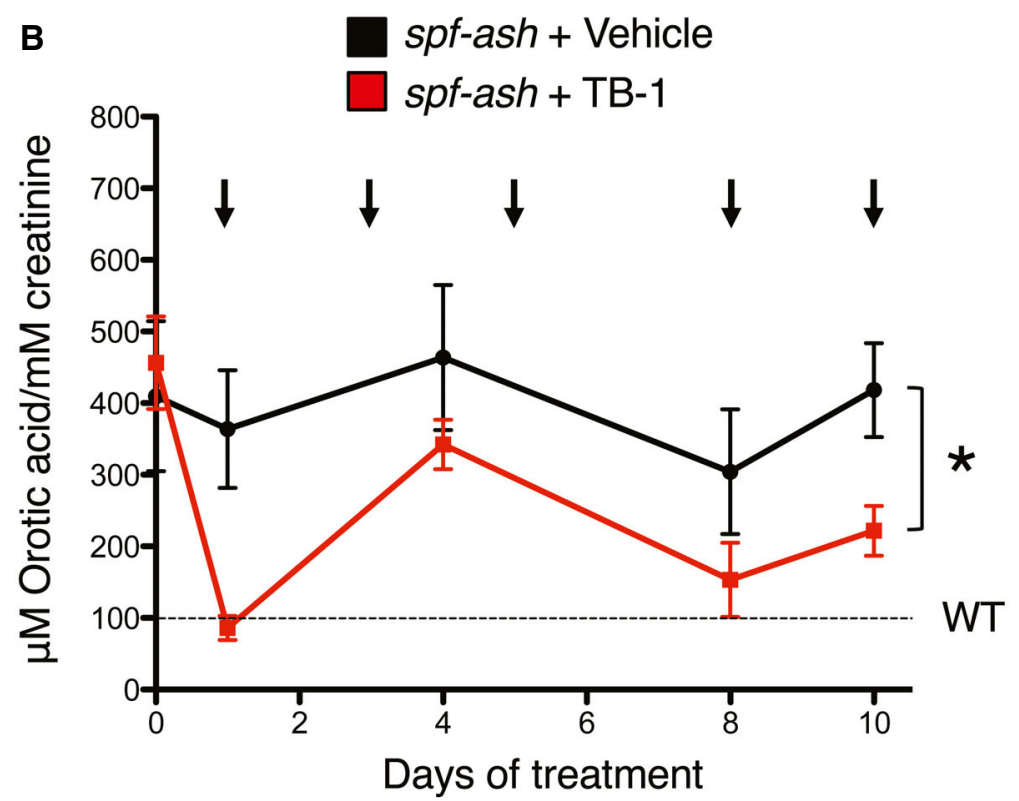

D
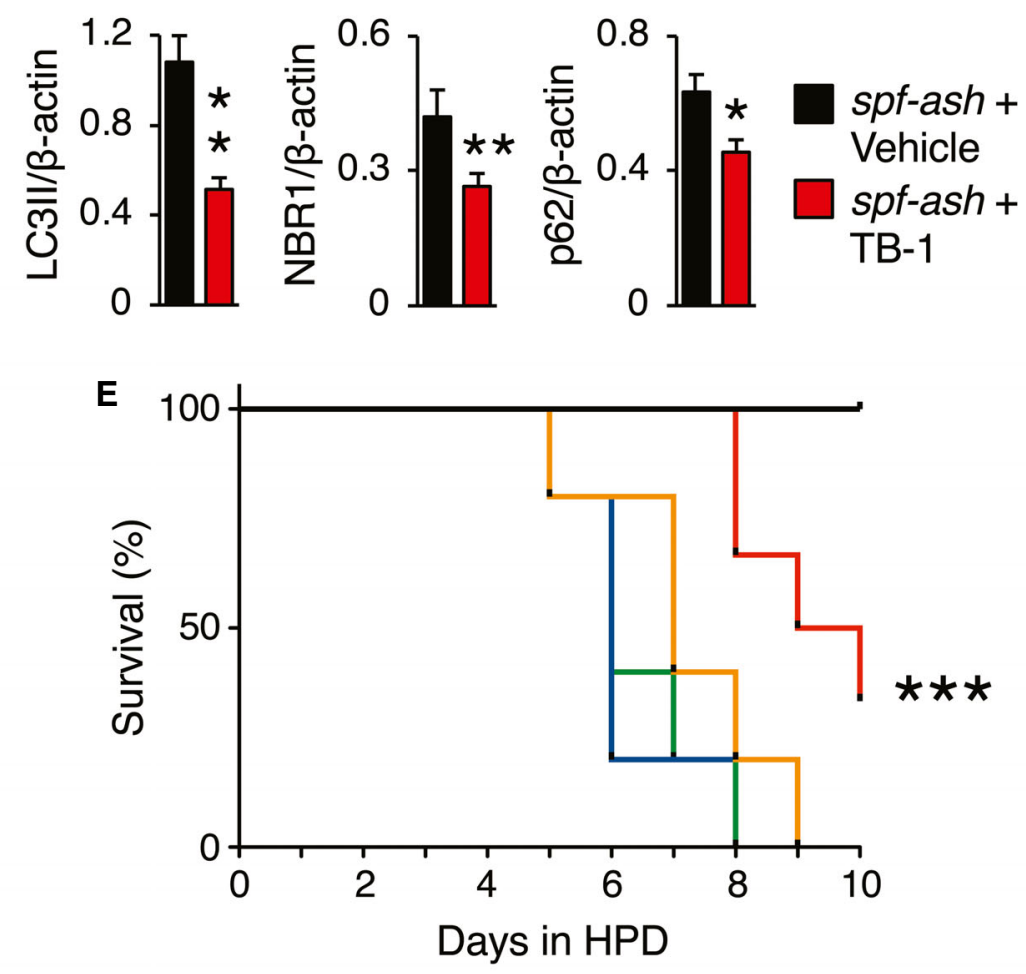

— WT

- spf-ash untreated

- spf-ash + TB-1

- spf-ash + scavenger + L-Arg

- spf-ash + TB-1 + scavenger + L-Arg 
Figure 1. Hyperactive Beclin-1 protects against hyperammonemia, and activation of hepatic autophagy improves the phenotype of OTC-deficient mice.

A Blood ammonia in 8-9-week-old C57BL/6) wild-type (WT) mice $(n=8)$ and Becn $1^{\text {F121A }}$ mice with constitutive activation of autophagy $(n=8)$ at baseline and $30 \mathrm{~min}$ after i.p. injection of $\mathrm{NH}_{4} \mathrm{Cl}(10 \mathrm{mmol} / \mathrm{kg})$. ${ }^{* *} P<0.01$ (Unpaired $t$-test). ns: not statistically significant difference.

B Urinary orotic acid of 12-week-old spf-ash mice treated with TB-1 (15 mg/kg, i.p) or vehicle at various times as indicated by the arrows ( $n=5 \mathrm{mice} / \mathrm{group})$. $* P<0.05$ (Two-way ANOVA)

C, D Western blotting and densitometric quantifications of autophagy markers (LC3II: autophagosomes; p62 and NBR1: cargo receptors) in livers of spf-ash mice harvested after 10 days of treatment with TB-1 or vehicle. $\beta$-actin was used as loading control. $n=5$ mice/group. ${ }^{* \star} p<0.01,{ }^{*} p<0.05$ (Unpaired $t$-test).

E Survival curves of spf-ash mice fed with a high protein diet (HPD) for 10 days and treated with TB-1 alone or combined with scavenger drug (Na-benzoate) and L-Arginine, or treated with scavenger drug (Na-benzoate) and L-Arginine, or left untreated. WT control were included ( $n=5 /$ group). ${ }^{* \star \star} P<0.001$ (Log-rank MantelCox test).

F Blood ammonia levels determined after 4 days under HPD $\left(n=5\right.$ mice/group); ${ }^{\star \star \star} P<0.001,{ }^{\star \star} P<0.01,{ }^{\star} P<0.05$ (One-way ANOVA).

Data information: Treatments in (E, F): Scavenger (Na-benzoate $250 \mathrm{mg} / \mathrm{kg} /$ day, i.p.) and L-arginine (L-Arg, $250 \mathrm{mg} / \mathrm{kg} / \mathrm{day}$, i.p.); TB-1 (15 mg/kg every 2 days, i.p). WT mice were age-, gender- and strain (C3H)-matched. All values are shown as averages \pm SEM. Exact $P$ values are reported in Appendix Table S1.

Source data are available online for this figure.

well separated from healthy WT controls but it was shifted towards non-diseased WT controls in $A s l^{\text {Neo/Neo }}$ mice injected with TB-1 (Fig 2G and Appendix Fig S1), suggesting that TB-1 corrects at least partially the liver metabolic deregulation caused by ASL deficiency. Notably, NMR confirmed that liver content of argininosuccinate, along with its two precursors citrulline and aspartate, was reduced (Fig EV4). Moreover, levels of key compounds of the TCA cycle (fumarate and succinate) and glucose were rescued by TB-1 (Fig EV4). In summary, TB-1 improved several biochemical alterations of ASA, confirming the efficacy of autophagy enhancer molecules for therapy of UCD.

\section{Tat-Beclin-1 reduces injury and abnormal glycogen deposition in livers with ASL deficiency}

Chronic hepatocellular injury is a common complication in patients with ASL deficiency (Mori et al, 2002; Yaplito-Lee et al, 2013; Baruteau et al, 2017; Ranucci et al, 2019). Despite the underlying mechanism triggering the liver disease remains unclear, evidence in human and mouse suggests that it is related to massive accumulation of cytoplasmic glycogen (Badizadegan \& Perez-Atayde, 1997; Bigot et al, 2017; Burrage et al, 2020). Moreover, because activation of autophagy was found to be effective in clearance of glycogen storage in glycogen storage diseases (Ashe et al, 2010; Spampanato et al, 2013; Martina et al, 2014; Farah et al, 2016), we investigated whether TB-1 promotes glycogen clearance in ASA livers. To this end, $A s l^{\mathrm{Neo} / \mathrm{Neo}}$ mice received protein-restricted diet and daily administration of Na-benzoate and L-Arg in combination with either TB-1 or vehicle, started on day 10 of life and lasting for 3 weeks. Consistent with previous data (Erez et al, 2011; Ashley et al, 2018; Baruteau et al, 2018; Burrage et al, 2020), vehicle-treated $A s l^{\mathrm{Neo} / \mathrm{Neo}}$ mice showed vacuolated hepatocyte cytoplasm by haematoxylin and eosin (H\&E) staining in contrast to WT mice, whereas TB-1 treatment markedly improved the microscopic changes of liver architecture (Fig 3A). Although body weight was unaffected (Fig EV5A), TB-1 treatment resulted in a trend of reduction in hepatomegaly (Fig EV5B) and a mild decrease in serum alanine aminotransferase (ALT) levels in $A s l^{\mathrm{Neo} / \mathrm{Neo}}$ mice (Fig EV5C). Moreover, Asl $l^{\mathrm{Neo} / \mathrm{Neo}}$ mice treated with TB-1 showed partial reduction of liver glycogen storage by periodic acid Schiff (PAS) staining (Fig 3A and B) and glycogen quantification (Fig 3C) compared to controls. Notably, glycogen accumulation was not observed in livers of spf-ash mice (Fig EV5D). Glycogen in hepatocytes is catabolized either in cytosol by the coordinated action of enzymes involved in glycogenolysis or in the lysosome by the acid glucosidase (Prats et al, 2018). Hepatic expression of glycogen phosphorylase (PYGL), the enzyme that catalyses the rate limiting step of glycogenolysis, was recently found to be reduced in $A s l^{\mathrm{Neo} / \mathrm{Neo}}$ mice, suggesting a mechanism responsible for aberrant glycogen accumulation in ASA (Burrage et al, 2020). We confirmed reduced PYGL protein levels in livers of $A s l^{\mathrm{Neo} / \mathrm{Neo}}$ mice, but they were unaffected by TB-1 (Fig 3D), suggesting that reduction of glycogen by TB-1 does not occur through rescue of the cytosolic glycogen degradation pathway. Moreover, when autophagy flux is increased by TB-1, glycogen degradation in lysosomes is efficiently achieved, as confirmed by electron microscopy (EM) analysis showing clearance of cytoplasmic glycogen accumulation (Fig 3E). Moreover, glycogen accumulation in $A s l^{\text {Neo/Neo }}$ mice resulted in displacement of organelles to the cell membrane as previously reported (Burrage et al, 2020), that is relieved by TB-1 (Fig 3E). Surprisingly, EM analysis also showed abundant intranuclear glycogen deposition in hepatocytes of $A s l^{\text {Neo/Neo }}$ mice, that was partially reduced by TB-1 (Fig 4A and B). In summary, in addition to promoting urea synthesis, TB-1 reduced abnormal glycogen storage in cytosol and nuclei of ASL-deficient hepatocytes.

\section{Discussion}

UCD are inborn errors of metabolism due to impaired clearance of toxic nitrogen. Despite current therapies, cumulative morbidity is still high in patients with UCD and thus, several experimental therapies have been investigated to improve clinical outcomes (Soria et al, 2019). We recently showed a role of hepatic autophagy in promoting ureagenesis and ammonia detoxification (Soria et al, 2018) that can be exploited for the development of novel therapies for hyperammonemia and UCD (Soria et al, 2018; Soria \& BrunettiPierri, 2018, 2019). In the present study, we investigated the efficacy of TB-1 peptide, a potent and specific agent that can activate autophagy in vivo, in two well-established mouse models of proximal and distal UCD. Induction of liver autophagy was found to improve several clinically relevant endpoints in these mice, supporting autophagy enhancement as a therapeutic strategy for UCD.

Autophagy plays a key role in liver physiology by supporting metabolism and promoting adaptation to stress. Specific modulation of autophagy has been recognized as a potential therapeutic strategy in various liver diseases (Allaire et al, 2019; Hazari et al, 2020). 
A

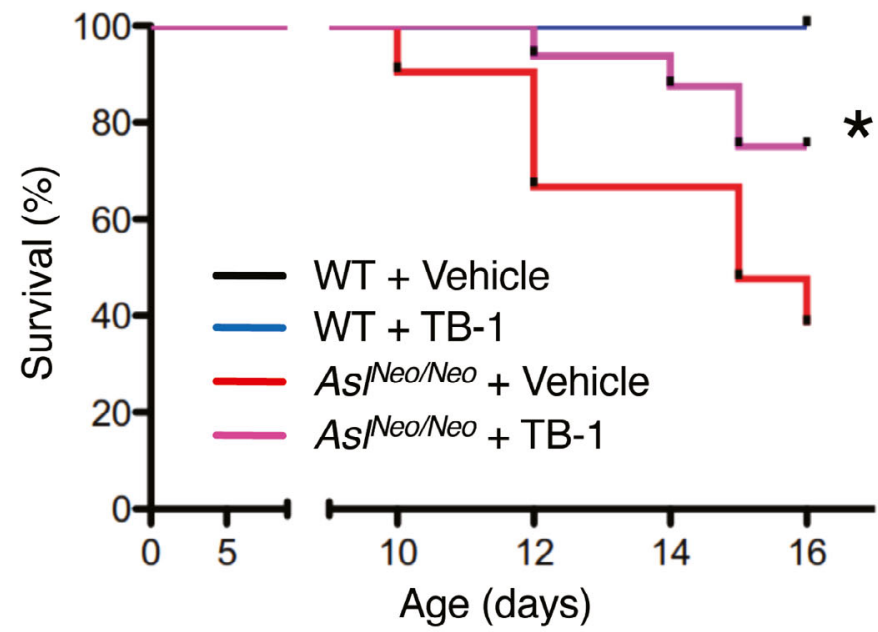

B
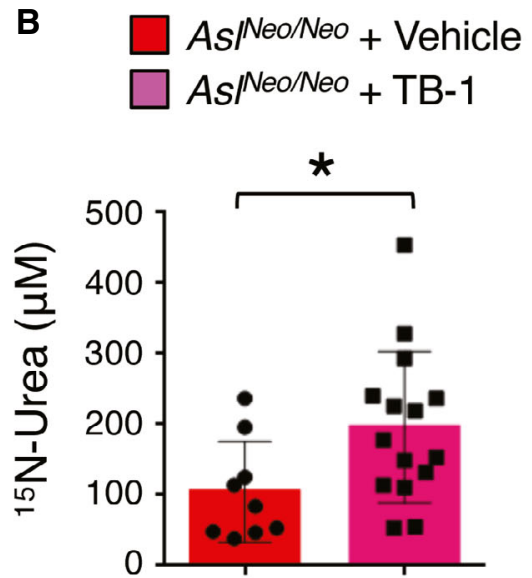

C Vehicle TB-1 D

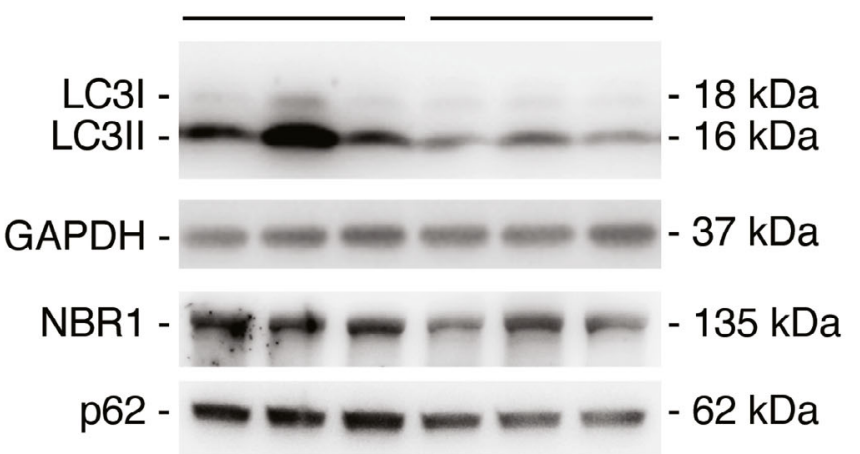

$\beta$-actin -

E

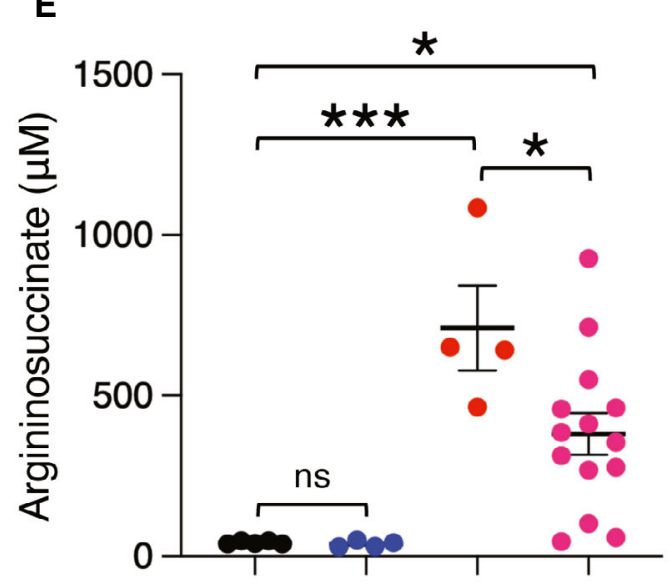

WT + Vehicle

$\square \mathrm{WT}+\mathrm{TB}-1$

$\square A s /{ }^{\mathrm{NeO} / \mathrm{NeO}}+$ Vehicle

As/ ${ }^{\mathrm{Neo} / \mathrm{Neo}}+\mathrm{TB}-1$
- 42 kDa

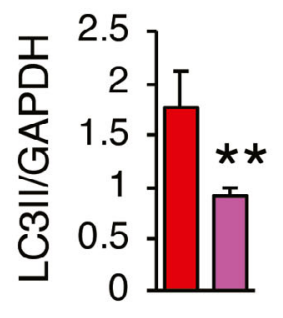

G

[T2]

$\mathbf{F}$

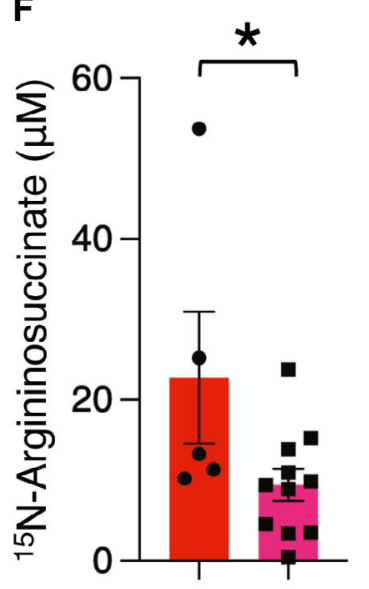

$A s / \mathrm{Neo} / \mathrm{Neo}+$ Vehicle

As/ $/ \mathrm{Neo} / \mathrm{NeO}+\mathrm{TB}-1$

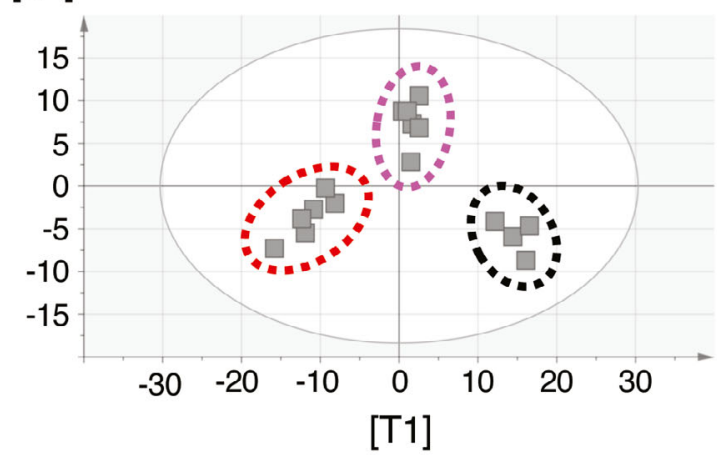

- WT + Vehicle

- $A s / \mathrm{Neo} / \mathrm{Neo}+$ Vehicle

- As/Neo/Neo + TB-1
$A s / /^{\mathrm{Neo} / \mathrm{Neo}}+$ Vehicle

$A s / \mathrm{Neo} / \mathrm{NeO}+\mathrm{TB}-1$

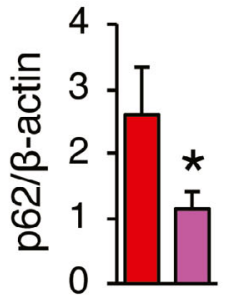


Figure 2. Enhancement of liver autophagy improves survival, increases ureagenesis, and corrects metabolic defects of ASL-deficient mice.

A Survival curves of $A s /$ Neo/Neo mice and age-matched wild-type (WT) controls treated with TB-1 (15 mg/kg, i.p., every 48 h starting at day 10 of age) or vehicle. WT + Vehicle $n=8 ; \mathrm{WT}+\mathrm{TB}-1 n=8 ;$ Asl ${ }^{\mathrm{Neo} / \mathrm{Neo}}+$ Vehicle $n=20 ;$ As/ ${ }^{\text {Neo/Neo }}+\mathrm{TB}-1 n=16$. ${ }^{*} \mathrm{P}<0.05$ (Log-rank Mantel-Cox test).

B Isotopic enrichment of ${ }^{15} \mathrm{~N}$-labelled urea in blood, 20 min after i.p. injection of ${ }^{15} \mathrm{NH}_{4} \mathrm{Cl}$ tracer $(4 \mathrm{mmol} / \mathrm{kg})$ in $A s /{ }^{\mathrm{Neo} / \mathrm{Neo}}$ mice treated with TB-1 $(n=15)$ or vehicle $(n=9) .{ }^{*} p<0.05$ (Unpaired $t$-test).

C Representative Western blotting bands of LC3, p62 and NBR1 in livers of As/ ${ }^{\text {Neo/Neo }}$ mice treated with TB-1 or vehicle. GAPDH and $\beta$-actin were used as loading controls.

D Densitometric quantifications. Asl ${ }^{\text {Neo/Neo }}+$ Vehicle $n=5$; Asl ${ }^{\text {Neo/Neo }}+$ TB-1 $n=9$. ${ }^{* \star} P<0.01$, ${ }^{\star} P<0.05$ (Unpaired $t$-test).

E Argininosuccinate in dried blood spots of WT and Asl ${ }^{\text {Neo/Neo }}$ mice injected with TB-1 or vehicle $\left(n=4-14\right.$ mice/group). ${ }^{* * *} P<0.001$, ${ }^{*} P<0.05$ (One-way ANOVA).

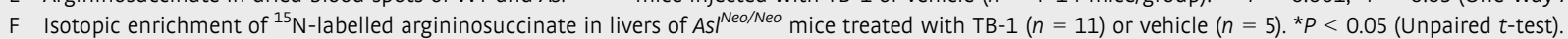

G Orthogonal Projection to Latent Structure-Discriminant Analysis (OPLS-DA) score plot obtained from high-resolution ${ }^{1} \mathrm{H}-\mathrm{NMR}$ spectroscopy performed on livers of vehicle-treated As/ Neo/Neo mice $(n=6), \mathrm{WT}$ controls $(n=4)$ and As/ Neo/Neo mice injected with TB-1 $(n=6)$. A statistical model with $\mathrm{R}^{2}=0.78($ goodness of fit), $\mathrm{Q}^{2}=0.57$ (power in prediction) and $P=0.0056$ was obtained. See also Appendix Fig S1.

Data information: All values are shown as averages \pm SEM. ns: not statistically significant difference. Exact $P$ values are reported in Appendix Table S1.

Source data are available online for this figure.

Obtaining specific modulation of autophagy has been a major challenge for clinical translation of autophagy enhancer molecules (Allaire et al, 2019). Being an essential regulator of autophagosome synthesis and maturation, Beclin-1 is an attractive target for autophagy-inducing drugs and small peptides affecting Beclin-1 interactions, such as TB-1 and its derivatives have been developed (ShojiKawata et al, 2013; Peraro et al, 2017). Moreover, drugs affecting post-translational modifications of Beclin-1 altering its function are also attractive (Hill et al, 2019). The Becn $1^{F 121 A}$ mouse model used in this work mimics the condition of disrupted interaction of Beclin1 with BCL2. In these mice, we found improved ureagenesis and increased ammonia detoxification capacity. Within the context of a normal functioning ureagenesis, the increase detected in Becn $1^{\text {F121A }}$ mice was relatively mild and corresponded to about $20-30 \%$. Nevertheless, such increase is still expected to provide significant clinical benefit in UCD. Additionally, the increased ureagenesis of $B e c n 1^{F 121 A}$ mice validates the inhibitors of the Beclin-1-BCL2 complex (Chiang et al, 2018) as targets for increasing ammonia detoxification.

We next investigated the efficacy of TB-1-mediated activation of hepatic autophagy for therapy of proximal and distal UCD using the most relevant mouse models for these disorders, the spf-ash and the $A s l^{\mathrm{Neo} / \mathrm{Neo}}$ mice for OTC and ASL deficiency, respectively (Moscioni et al, 2006; Prieve et al, 2018; Kurtz et al, 2019; Soria et al, 2019). In spf-ash mice treated with TB-1, we detected reduced urinary orotic aciduria under standard and high protein diet. Importantly, combined with clinically available drugs enhancing ammonia excretion (Na-Benzoate) and urea synthesis (L-Arg), TB-1 was also effective in increasing survival of spf-ash mice challenged with a high protein diet. These data suggest that liver autophagy enhancement cooperates with current treatment in improving the phenotype of OTC deficiency. In ASA mice, we also found that hepatic enhancement of autophagy increased ureagenesis and survival, and reduced argininosuccinate levels along with generalized rescue of the metabolic derangement, as suggested by liver metabolomic analyses. In summary, TB-1 improved the phenotypes of two UCD animal models, supporting the potential of autophagy enhancement for therapy of hyperammonemia due to defects of the urea cycle.

Increased liver autophagy by TB-1 provides amelioration but not a cure for UCD. The therapeutic potential of TB-1 could be especially exploited in newborns or infants with UCD in their early disease stages before more definitive treatments, such as liver transplantation or gene therapy can be safely and effectively performed. For liver-directed gene therapy with adeno-associated viral (AAV) vectors, efficacy is gradually lost during mouse growth as a consequence of dilution of episomal vector genomes in dividing hepatocytes (Cunningham et al, 2009; Baruteau et al, 2018). Hence, TB-1 can be viewed as a bridge treatment until affected infants reach an age that permits sustained transgene expression by gene therapy. Interestingly, co-administration of autophagy enhancers with AAV vectors markedly improved transgene expression (Hosel et al, 2017) and thus, TB-1 could have the dual action of increasing AAV transduction and improving metabolic control. Moreover, onset of hepatic gene expression by AAV typically requires $2-3$ weeks, and thus, TB-1 might also treat the metabolic defect until high levels of gene expression are achieved.

Interestingly, in ASA mice TB-1 also resulted in increased clearance of intracellular glycogen accumulation. Disposal of

Figure 3. Enhancement of autophagy reduces hepatocellular injury and glycogen storage in ASL-deficient mice.

A Haematoxylin and eosin (H\&E, upper panels) and periodic acid Schiff (PAS, lower panels) staining of liver samples harvested from wild-type (WT) and Asl ${ }^{\text {Neo/Neo }}$ mice treated with TB-1 or vehicle. Scale bars: $500 \mu \mathrm{m}$.

B Computational analysis of PAS staining ( $n \geq 4$ mice/group). ${ }^{*} p<0.01,{ }^{*} p<0.05$ (One-way ANOVA).

C Quantification of hepatic glycogen in vehicle $(n=6)$ - and TB-1-treated Asl ${ }^{\text {Neo/Neo }}$ mice $(n=12)$ compared to WT $(n=5)$ controls. ${ }^{* \star} P<0.01$, ${ }^{\star} P<0.05($ One-way ANOVA).

D Representative Western blotting bands and densitometric quantification of PYGL in livers of WT and As/ ${ }^{\text {Neo/Neo }}$ mice treated with either with TB-1 or vehicle $(n=4$ mice/group). ${ }^{*} P<0.05$ (One-way ANOVA). GAPDH was used as loading control.

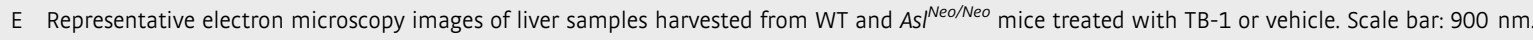

Data information: All values are shown as averages \pm SEM. Exact $P$ values are reported in Appendix Table S1.

Source data are available online for this figure. 

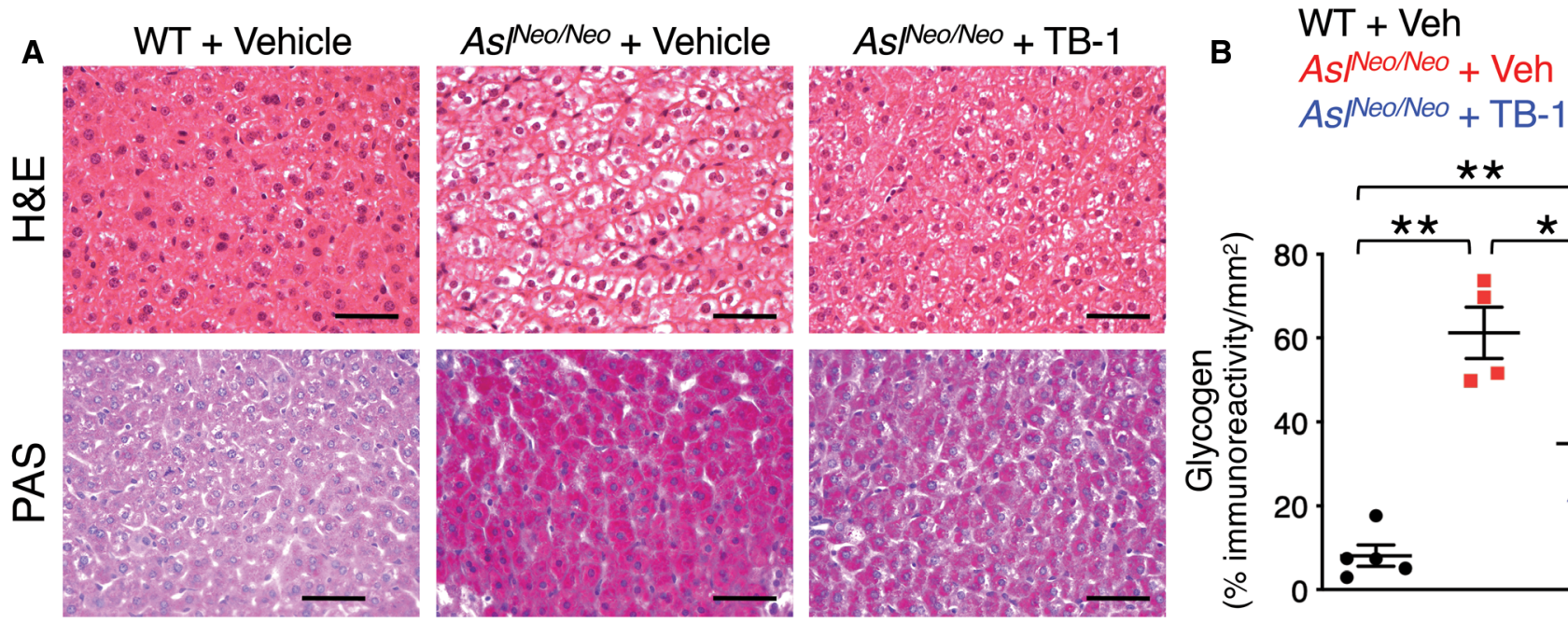

C

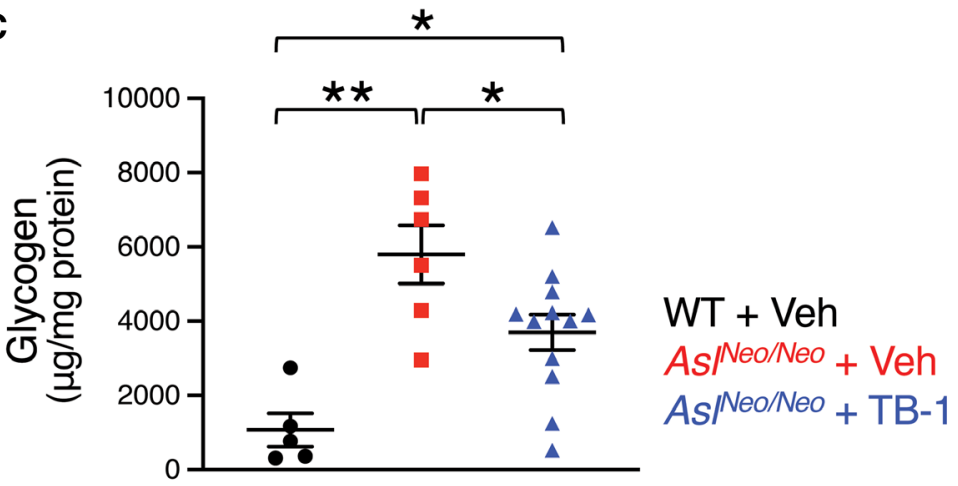

E

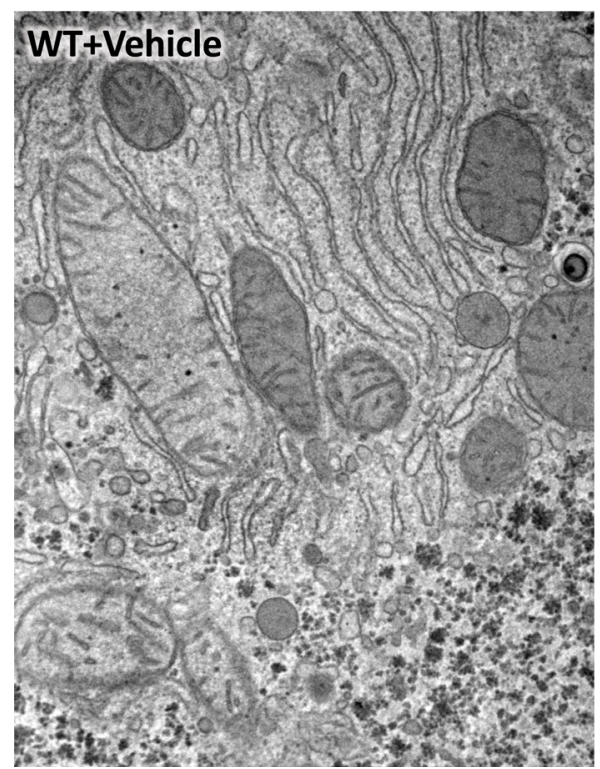

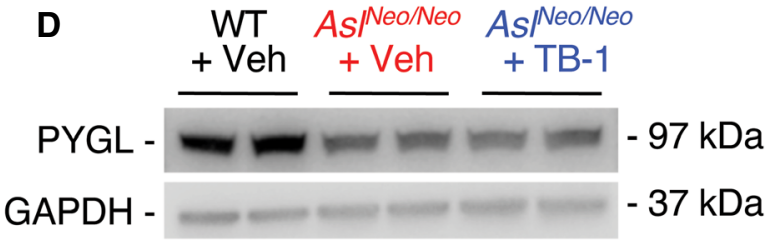

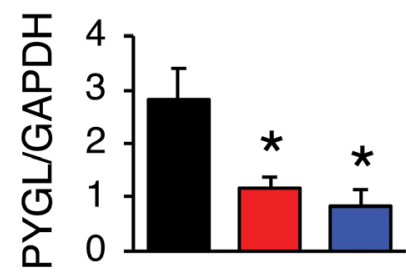

Figure 3.

carbohydrates such as glycogen via autophagy plays a crucial role in glucose homeostasis (Karsli-Uzunbas et al, 2014). This finding is consistent with previous studies in glycogen storage diseases type 1 and 2 showing that either genetic or pharmacologic activation of autophagy reduced glycogen storage (Ashe et al, 2010; Spampanato et al, 2013; Martina et al, 2014; Farah et al, 2016). Consistent with a previous study (Burrage et al, 2020), we found that PYGL was reduced in ASL-deficient mice and thus, increased glycogen 
A
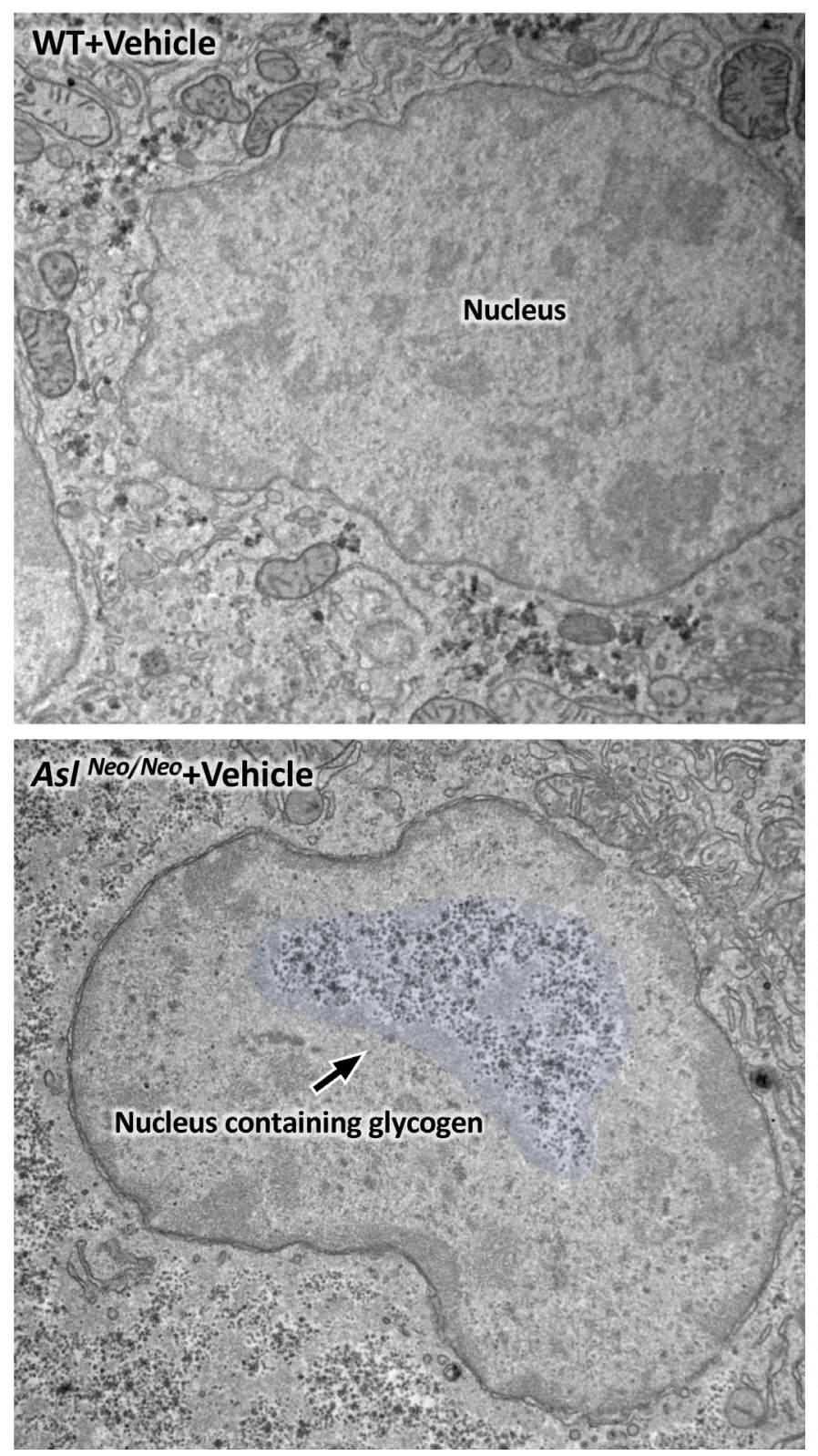
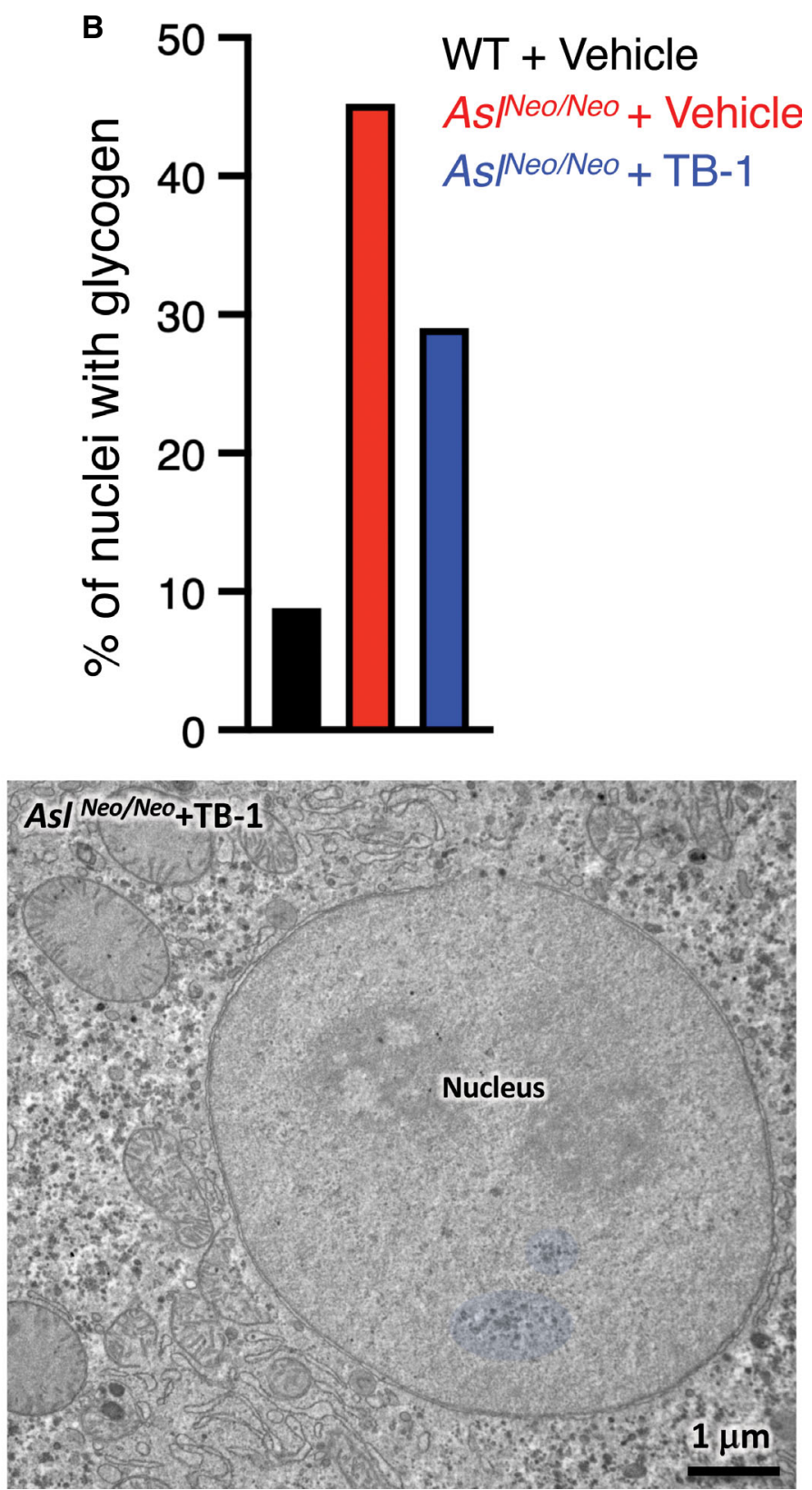

Figure 4. TB-1 reduces intra-nuclear glycogen deposition in ASL-deficient mice.

A Representative electron microscopy images of liver samples harvested from wild-type (WT) and Asl Neo/Neo mice treated with TB-1 or vehicle. False colour on the images indicates glycogen within the nuclei. Scale bar: $1 \mu \mathrm{m}$.

B Quantification of nuclei containing glycogen (approx. 180 nuclei were analysed in total per condition, $n=3$ mice/group).

Data information: All values are shown as averages \pm SEM. ns: not statistically significant difference.

Source data are available online for this figure.

degradation mediated by TB-1 occurred independently from impaired cytosolic PYGL-dependent degradation of glycogen.

Glycogen clearance induced by TB-1 restored physiologic organelle distribution within the cell. Abnormal glycogen deposition in UCD livers occurs independently from metabolic syndrome (Bigot et al, 2017) and has been reported in patients with OTC deficiency and other UCD (Badizadegan \& Perez-Atayde, 1997; Mori et al, 2002; Yaplito-Lee et al, 2013; Baruteau et al, 2017; Bigot et al, 2017;
Ranucci et al, 2019). However, spf-ash mice showed normal hepatic glycogen storage. Intriguingly, we found glycogen accumulation also in nuclei of ASA hepatocytes. Nuclear accumulation of glycogen was recently associated to epigenetic changes in gene expression and cancer (Sun et al, 2019). In normal cells, nuclear glycogenolysis provides a carbon pool for proper histone acetylation, whereas in cancer cells suppression of nuclear glycogen catabolism is associated with changes in histone acetylation and gene expression, and 
cancer progression (Sun et al, 2019). Liver cancer is an emerging feature of UCD (Wilson et al, 2012; Koo et al, 2017; Wang et al, 2019). Therefore, besides improved ureagenesis, the reduced cytoplasmic and intra-nuclear glycogen mediated by TB-1 might provide further long-term clinical benefits preventing progression of chronic liver damage. However, this hypothesis would need further investigation and available mouse models of UCD have not been reported to have an increased frequency of liver cancer. The newly generated OTC knock-out mouse model that develops liver fibrosis and chronic liver damage (Wang et al, 2017) might be a suitable model to investigate this issue in long-term studies.

We previously found that TB-1 increases ureagenesis by furnishing the urea cycle with key intermediate metabolites and preventing ammonia-induced depletion of ATP (Soria et al, 2018). Whether this mechanism is also responsible for increased ureagenesis in ASL deficiency cannot be established. Asl ${ }^{\mathrm{Neo} / \mathrm{Neo}}$ mice have massive accumulation of argininosuccinate secondary to deficiency of ASL that breaks down argininosuccinate into arginine and fumarate. In

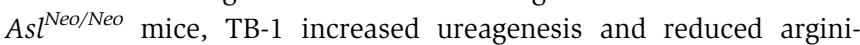
nosuccinate despite the lack of increased ASL activity. Although no changes in ASL enzyme activity were detected, the enzyme assay might not reflect the enzyme in vivo activity. Alternatively, other mechanisms can be hypothesized. For instance, TB-1 might improve metabolic channelling, i.e. reversible specific assembly of enzyme clusters that accelerate processing of metabolite intermediates (Castellana et al, 2014; Pareek et al, 2020). Notably, channelling of urea cycle intermediates has been found between mitochondria and cytosol where ureagenesis takes place (Cheung et al, 1989; Cohen et al, 1992). This channelling could be particularly affected in $A s l^{\mathrm{Neo} / \mathrm{NeO}}$ mouse hepatocytes displaying aberrant distribution of their sub-cellular compartments that is partially corrected by TB-1, as confirmed by the ultrastructural studies performed in this work.

In conclusion, this study shows a key role of liver autophagy in nitrogen homeostasis and indicates that Beclin-1 as a druggable target for therapy of hyperammonemia and UCD. Moreover, these findings show that enhancement of hepatic autophagy is beneficial in UCD through: (i) correction of the underlying metabolic abnormalities by supporting residual ureagenesis activity and, (ii) reduction of the aberrant intracellular (cytosolic and nuclear) glycogen burden that might prevent long-term hepatotoxicity.

\section{Materials and Methods}

\section{Mouse studies}

All mouse procedures were performed in accordance with regulations and were authorized by either the Italian Ministry of Health or the UK Home Office. Becn1 $1^{F 121 A}$ (B6.129(Cg)-Becn1tm1.1Hec/J) mice were previously described (Rocchi et al, 2017; Fernandez et al, 2018) and were maintained on a C57BL/6 background. Wild-type (WT) littermates were used as controls. For acute ammonia challenges, male and female WT and Becn $1^{F 121 A}$ mice were starved overnight before the i.p. injection of $10 \mathrm{mmol} / \mathrm{kg}$ of ${ }^{15} \mathrm{~N}$-labelled ammonium chloride (98\% enriched in ${ }^{15} \mathrm{~N}$, Sigma) dissolved in water. Blood samples were collected by retro-orbital bleedings at baseline, 5, 15, and 30 min post-injection. The amount of ${ }^{15} \mathrm{~N}$ labelled urea in sera was quantified by gas chromatography-mass spectrometry (GC-MS) analysis at the Metabolic Core of The Children's Hospital of Philadelphia (Philadelphia, PA). Mice were sacrificed by cervical dislocation, and liver samples were harvested for analyses. Breeding pairs of spf-ash mice (B6EiC3Sn a/A-OTC ${ }^{\text {Spf-Ash }}$ / J) were purchased from Jackson Laboratories (Cat\# 001811) and housed in individually ventilated cages, maintaining a temperature of $22^{\circ} \mathrm{C}\left( \pm 2^{\circ} \mathrm{C}\right)$, relative humidity of $55 \%$ ( $\left.\pm 10 \%\right), 15-20$ air exchanges per hour and 12-h light/12-h dark cycle and receiving a standard chow diet and water ad libitum. 12-week-old male spf-ash mice received an i.p. injection of TB-1 D-11 retroinverso form peptide (Novus Biologicals; Cat\# NBP2-49888) at the dose of $15 \mathrm{mg} / \mathrm{kg}$ [dissolved in phosphate buffer saline (PBS)] every $48 \mathrm{~h}$ for a total period of 10 days. Animals were daily monitored and weighted. Urine samples were collected at the indicated time points to measure orotic acid. A control group of spf-ash animals were injected with vehicle only. For high protein diet challenge, 12-weekold male spf-ash mice were maintained on a $51 \%$-protein diet (U8959 version 142, Safe-diets) for 10 days. TB-1 peptide was delivered by i.p. injection at the dose of $15 \mathrm{mg} / \mathrm{kg}$ every $48 \mathrm{~h} .60 \mathrm{mg} / \mathrm{ml}$ Na-Benzoate (Sigma; Cat\# 18106) and $60 \mathrm{mg} / \mathrm{ml} \mathrm{L-Arg} \mathrm{(Sigma,} \mathrm{Cat \#}$ A5006) dissolved in PBS were i.p. injected at the dose of $250 \mathrm{mg} / \mathrm{kg}$ Na-Benzoate, $250 \mathrm{mg} / \mathrm{kg}$ L-Arg every $24 \mathrm{~h}$. As controls, a group of spf-ash mice were injected with vehicle only and a group of WT mice were used. Animals were daily monitored and weighted. Blood samples were collected by submandibular bleeding at day 4 to measure ammonia concentration. Urines were collected at baseline and day 4 for measurements of orotic acid.

Asl $l^{\mathrm{Neo} / \mathrm{Neo}}$ mice (B6.129S7-Asl tm1Brle $_{\mathrm{J}}$ ) were purchased from Jackson Laboratory (Bar Harbor, ME) and maintained on standard rodent chow (Harlan 2018, Teklab Diets, Madison, WI; protein content $18 \%$ ) with free access to water in a $12 \mathrm{~h}$ light/12 h dark environment. For mouse genotyping, DNA extraction from tail clips was performed as described previously (Baruteau et al, 2018). For longterm experiment, all WT and $A s l^{\mathrm{Neo} / \mathrm{Neo}}$ mice received a supportive treatment modified (Baruteau et al, 2018) including a reducedprotein diet (5CR4, Labdiet, St Louis, MO; protein content $14.1 \%$ ) and daily i.p. injections of Na-benzoate $(0.5 \mathrm{~g} / \mathrm{kg} /$ day $)$ and L-Arg $(0.5 \mathrm{~g} / \mathrm{kg} /$ day $)$ from day 10 to day 30 . Treated $A s l^{\text {Neo/Neo }}$ mice received $15 \mathrm{mg} / \mathrm{kg}$ of TB-1 i.p. three times per week (Monday, Wednesday, Friday). Control animals received vehicle (i.e. PBS). Male WT and $A s l^{\mathrm{Neo} / \mathrm{Neo}}$ mice received three i.p. injections over 5 or 20 days with either PBS or TB-1 from 10 days old onwards. Concomitantly, these mice received daily supportive treatment to improve survival until day 30. WT littermates were used as controls. For all experiments, WT and $A s l^{\mathrm{Neo} / \mathrm{Neo}}$ littermates were housed in the same cages. WT and mutant pups remained in cages with their mothers until day 30. Pups and their mothers were fed with the same diet. Mice had free access to diet and were not fasted before sacrifice.

\section{Biochemical measurements}

Blood ammonia levels were measured by ammonia colorimetric assay kits (BioVision Incorporated; Cat\# K370-100 or Sigma; Cat\#AA0100) according to the manufacturer's instructions. Circulating ALT levels were analysed with a Fuji Dri-Chem NX500 (FUJIFILM, Tokyo, Japan). Orotic acid was purchased from SigmaAldrich. The isotopically labelled internal standard orotic acid was purchased from Cambridge Isotope Laboratories, Inc. The 
quantitative experiments were done using as internal standard the isotopically labelled $1,3-{ }^{15} \mathrm{~N}_{2}$ orotic acid in $200 \mu \mathrm{M}$ concentration both for calibration curve and samples. A typical calibration curve ranged from 15 to $300 \mu \mathrm{M}$ with excellent linearity $\left(R^{2}>0.99\right)$. A Bruker (Bremen, Germany) amaZon SL bench-top ion trap mass spectrometer, equipped with an electrospray source, was employed for this study. The source was operated in negative ion mode with a needle potential of $4,500 \mathrm{~V}$ and a gas flow of $12 \mathrm{l} / \mathrm{min}$ of nitrogen with heating at $200^{\circ} \mathrm{C}$. The chromatographic separations for quantitative experiments were performed using a series 1260 Agilent Technologies (Waldbronn, Germany) HPLC with auto sampler controlled from the Bruker Hystardata system. A Phenomenex (Torrance, USA) HPLC column Gemini C18 $5 \mu \mathrm{m}, 110 \AA$, $2 \times 150 \mathrm{~mm}$ was employed. Column flow rate was $0.4 \mathrm{ml} / \mathrm{min}$ and elution was performed using 5 min wash time after $10 \mu$ injection and a $3 \mathrm{~min}$ gradient from water with $0.1 \%$ formic acid to $90 \%$ acetonitrile with $0.1 \%$ formic acid. The tandem mass spectrometry (MS/MS) transitions used for the quantitative experiments (multiple reaction monitoring, MRM) were $m / z$ 155.1-111.1 (orotic acid) and 157.1 to 113.1 (1,3-15N2 orotic acid). The acquired data were processed using the Bruker Compass Data Analysis proprietary software. Creatinine was measured using the Mouse Creatinine kit (Crystal Chem; Cat\# 80350) following the manufacturer's guidelines and used to normalize orotic acid values in the urine.

Mass spectrometry analysis of argininosuccinic acid in dried bloodspots was performed as previously described (Baruteau et al, 2019b). Briefly, blood spots on a Guthrie card were dried at room temperature for $24 \mathrm{~h}$. $3 \mathrm{~mm}$-diameter punch from dried blood spots were used to measure argininosuccinic acid by liquid chromatography-tandem mass spectrometry (LC-MS/MS). A punch was incubated for $15 \mathrm{~min}$ in sonicating water bath in $100 \mu \mathrm{l}$ of methanol containing stable isotopes used as internal standards. A 4:1 volume of methanol was added to precipitate contaminating proteins. The supernatant was collected and centrifuged at 16,000 $\mathrm{g}$ for $5 \mathrm{~min}$ before separation on a Waters Alliance 2795 LC system (Waters, Midford, USA) using a XTerra ${ }^{\circledR}$ RP18, $5 \mu \mathrm{m}, 3.9 \times 150 \mathrm{~mm}$ column (Waters, Midford, USA). The mobile phases were (A) methanol and (B) $3.7 \%$ acetic acid. Detection was performed using a tandem mass spectrometer Micro Quattro instrument (Micromass UK Ltd, Cheshire, UK) using multiple reaction monitoring in positive ion mode. Data were analysed using Masslynx 4.1 software (Micromass UK Ltd, Cheshire, UK).

Mass spectrometry analysis of ${ }^{15} \mathrm{~N}$-labelled argininosuccinic acid in liver samples was adapted from Prinsen et al (2016). Briefly, liver samples were homogenized in $400 \mu \mathrm{l}$ of mixture of ice-cold methanol:acetonitrile:water (ratio of 5:3:2) containing internal standard (2 nmol/l, L-citrulline-d7, CDN Isotopes, Pointe-Claire, Quebec) and centrifuged at $17,000 \mathrm{~g}$ for $20 \mathrm{~min}$ at $4{ }^{\circ} \mathrm{C}$. Supernatants were dried using Eppendorf ${ }^{\circledast}$ Concentrator Plus and resuspended in $0.05 \mathrm{M} \mathrm{HCl} .80 \mu \mathrm{l}$ of the resuspended mixture was mixed with $280 \mu \mathrm{l}$ of solvent A $(10 \mathrm{mM}$ ammonium formate, $85 \%$ Acetonitrile $+0.15 \%$ formic acid), centrifuged at $17,000 \mathrm{~g}$ for $5 \mathrm{~min}$ and filtered with $0.2 \mu \mathrm{M}$ PTFE membrane filter (Thermo-Fisher Scientific, Rockford, IL, USA) before analysis by hydrophilic interaction liquid chromatography coupled with tandem mass spectrometry. Amino acid chromatography separation was performed in Acquity UltraPure Liquid Chromatography (UPLC)-system (Waters, Manchester, UK) using Acquity UPLC BEH Amide column $(2.1 \times 100 \mathrm{~mm}$,
$1.7 \mu \mathrm{m}$ particle size) and Van Guard ${ }^{\mathrm{TM}}$ UPLC BEH Amide precolumn $(2.1 \times 5 \mathrm{~mm}, 1.7 \mu \mathrm{m}$ particle size) (Waters Limited, UK). The mobile phases were (A) $10 \mathrm{mM}$ ammonium formate in $85 \%$ acetonitrile and $0.15 \%$ formic acid and (B) $15 \mathrm{mM}$ ammonium formate containing $0.15 \%$ formic acid, $\mathrm{pH}$ 3.0. Detection was performed using a tandem mass spectrometer Xevo TQ-S (Waters, UK) using multiple reaction monitoring in positive ion mode. The dwell time was set automatically with MRM-transition of $292.2>116.98$ and $274.2>70.2$ for ${ }^{15} \mathrm{~N}$-ASA and ${ }^{15} \mathrm{~N}$-ASA anhydrides, respectively. L-Citrulline-d7 was used as internal standard control. Argininosuccinate data were analysed using Masslynx 4.2 software (Micromass UK Ltd, Cheshire, UK).

\section{In vivo ${ }^{15} \mathrm{~N}$-ureagenesis in Asl ${ }^{\mathrm{Neo} / \mathrm{NeO}}$ mice}

Vehicle- and TB-1-treated $A s l^{\mathrm{Neo} / \mathrm{Neo}}$ mice received an i.p. injection of $4 \mathrm{mmol} / \mathrm{kg}$ of ${ }^{15} \mathrm{~N}$-labelled ammonium chloride $\left({ }^{15} \mathrm{NH}_{4} \mathrm{Cl}\right.$, Cambridge Isotope Laboratories) $20 \mathrm{~min}$ before terminal blood collection via cardiac puncture. Blood was collected in 1:10 volume of sodium citrate and centrifuged at 13,000 $\mathrm{g}$ for $5 \mathrm{~min}$. Plasma was collected and snap-frozen in dry ice. ${ }^{13} \mathrm{C},{ }^{15} \mathrm{~N}_{2}$-urea (Sigma) was added to all samples as an internal standard, and samples were derivatized in a two-stage procedure. Firstly, urea was cyclized with 1,1,3,3-Tetramethoxypropane (Sigma-Aldrich) under acidic conditions to obtain 2-hydroxypyrimidine (2HP). 2HP was then coupled with 2,3,4,5,6-Pentafluorobenzyl bromide (Sigma-Aldrich) to yield a derivative that, upon negative ion chemical ionization gas chromatography mass spectrometry, yields a negatively charged 2-HP fragment that includes the nitrogen and carbon atoms of the starting urea. Ions of mass/charge 95 (2HP from ${ }^{12} \mathrm{C},{ }^{14} \mathrm{~N}_{2}$-urea), 96 $\left({ }^{12} \mathrm{C},{ }^{15} \mathrm{~N},{ }^{14} \mathrm{~N}\right.$-urea derived from ${ }^{15} \mathrm{~N}$-ammonium chloride or ${ }^{13} \mathrm{C},{ }^{14} \mathrm{~N}_{2}$-urea) and $98\left({ }^{13} \mathrm{C},{ }^{15} \mathrm{~N}_{2}\right.$-urea internal standard) were analysed, and quantified with suitable standard curves $(95 / 98$ for unlabelled urea, $96 / 98$ for ${ }^{15} \mathrm{~N}$-urea). Unlabelled urea concentration was calculated from the $95 / 98$ ratio, the contribution of unlabelled urea to mass 96 calculated from the natural abundances of the atoms in the fragment $\left(\mathrm{C}_{4} \mathrm{H}_{3} \mathrm{~N}_{2} \mathrm{O}^{-}\right)$, and ${ }^{15} \mathrm{~N}$-urea calculated from the $96 / 98$ ratio minus the contribution of unlabelled urea to mass 96 .

\section{Metabolite profiling of liver tissue by ${ }^{1} \mathrm{H}-\mathrm{NMR}$}

Livers were mechanically disrupted to extract the metabolites of interest (lipids, carbohydrates, amino acids, and other low-molecular weight metabolites) while leaving other compounds (DNA, RNA, and proteins) in the tissue pellet. Homogenization of $200 \mathrm{mg}$ of frozen tissue samples was carried out in cold methanol $(8 \mathrm{ml} / \mathrm{g}$ of tissue, wet weight), and cold water $(1.7 \mathrm{ml} / \mathrm{g}$ of tissue, wet weight) with UltraTurrax for $2 \mathrm{~min}$ on ice. Four $\mathrm{ml}$ of chloroform per $\mathrm{g}$ of tissue (wet weight) were added and the homogenate was gently stirred and mixed on ice for $10 \mathrm{~min}$ (the solution must be monophasic). Then, additional $4 \mathrm{ml}$ of chloroform per $\mathrm{g}$ of tissue (wet weight), and $4 \mathrm{ml}$ of water per g of tissue (wet weight) were added and the final mixture was well shaken and centrifuged at $12,000 \mathrm{~g}$ for $15 \mathrm{~min}$ at $4^{\circ} \mathrm{C}$. This procedure separates three phases: water/ methanol on the top (aqueous phase with the polar metabolites), denatured proteins and cellular debris in the middle, and chloroform at the bottom (lipid phase with lipophilic compounds). The upper and the lower layers were transferred into glass vials, the solvents 
removed under a stream of dry nitrogen, and stored at $-80^{\circ} \mathrm{C}$ until analysis. Polar extracts were resuspended in $700 \mu \mathrm{PBS}, \mathrm{pH} 7.4$ with $10 \% \mathrm{D}_{2} \mathrm{O}$ for lock procedure, and then transferred into an NMR tube. High-resolution one-dimensional (1D) spectra were recorded at $600.13 \mathrm{MHz}$ on a Bruker Avance III-600 spectrometer (Bruker BioSpin GmbH, Rheinstetten, Germany) equipped with a TCI CryoProbe ${ }^{\mathrm{TM}}$ fitted with a gradient along the Z-axis, at a probe temperature of $27^{\circ} \mathrm{C}$, using the excitation sculpting sequence for solvent suppression. Spectra were referenced to internal $0.1 \mathrm{mM}$ sodium trimethylsilylpropionate, assumed to resonate at $\delta=0.00 \mathrm{ppm}$.

\section{NMR data processing and statistical analysis}

The spectral 0.50-9.40 ppm region of the ${ }^{1} \mathrm{H}$-NMR spectra was automatically data reduced to integrated regions (buckets) of 0.04-ppm each using the AMIX 3.6 package (Bruker Biospin $\mathrm{GmbH}$, Rheinstetten, Germany). The residual water resonance region (4.72$5.10 \mathrm{ppm}$ ) was excluded, and the integrated region was normalized to the total spectrum area. To differentiate liver tissues through NMR spectra, we carried out a multivariate statistical data analysis using projection methods as previously reported (Soria et al, 2018).

\section{Enzyme activity assays}

OTC enzyme activity was determined in total liver protein extracts as reported previously (Ye et al, 1996) with minor modifications. One $\mu \mathrm{g}$ of total liver protein extract (in lysis buffer: $0.5 \%$ Triton-X, $10 \mathrm{mM}$ Hepes pH 7.4, $2 \mathrm{mM}$ DTT) was added to $350 \mu$ l of reaction mixture $(5 \mathrm{mM}$ ornithine, $15 \mathrm{mM}$ carbamyl phosphate and $270 \mathrm{mM}$ triethanolamine, $\mathrm{pH} 7.7$ ) and incubated at $37^{\circ} \mathrm{C}$ for $30 \mathrm{~min}$. The reaction was then stopped by adding $125 \mu \mathrm{l}$ of $3: 1$ phosphoric/sulphuric acid solution followed by $25 \mu \mathrm{l}$ of $3 \%$ 2,3-butanedione monoxime and incubated at $95^{\circ} \mathrm{C}$ for $15 \mathrm{~min}$ in the dark. Citrulline production was determined by measuring the absorbance at $490 \mathrm{~nm}$.

For ASL activity, liver samples were snap-frozen in dry ice at time of collection. Protein extraction was performed on ice. Liver samples were homogenized with the Qiagen Bead Tissue Lyser (Qiagen Manchester Ltd, Manchester, UK) in $500 \mu \mathrm{l}$ of $50 \mathrm{mM}$ phosphate buffer ( $\mathrm{pH}$ 7.4) with EDTA-free proteinase inhibitor cocktail (Roche, Basel, Switzerland) at a frequency of 30 for $30 \mathrm{~s}$. Homogenates were centrifuged at $13,000 \mathrm{~g}$ for $10 \mathrm{~min}$ at $4^{\circ} \mathrm{C}$. Protein quantification of the supernatant was performed using the Pierce ${ }^{\mathrm{TM}} \mathrm{BCA}$ protein assay kit (Thermo-Fisher Scientific, Rockford, IL, USA) according to the manufacturer's instructions. ASL activity was measured by synthesis of fumarate in an excess of argininosuccinate as previously described (Baruteau et al, 2018). Fumarate was measured with the Fumarate Assay Kit (Sigma; Cat\# MAK060) according to manufacturer's instructions.

\section{Periodic acid Schiff staining}

The staining was performed according to the Standard Operating Procedure protocol at the Histopathology laboratory, Great Ormond Street Hospital, London. Sections were dewaxed in xylene, hydrated down through graded alcohol solutions to water, incubated for $10 \mathrm{~min}$ in $0.5 \%$ periodic acid, rinsed in distilled water, stained for 10 min with Schiff reagent, then rinsed in distilled water. Sections were then washed for $5 \mathrm{~min}$ in running tap water and counterstained in $1 \%$ eosin for $1 \mathrm{~min}$, rinsed briefly in running tap water and dehydrated through ascending grades of alcohol. Sections were then cleared in xylene and mounted. For haematoxylin and eosin (H\&E) staining, liver sections were processed according to standard protocols.

For quantitative PAS staining quantification, ten random images per liver section were captured with a microscope camera (DFC420; Leica Microsystems, Milton Keynes, UK) and software (Image Analysis; Leica Microsystems). Quantitative analysis was performed with thresholding analysis using the Image-Pro Premier 9.1 software (Rockville, MD, USA).

\section{Hepatic glycogen determination}

Liver content of glycogen was determined by using a colorimetric glycogen assay kit (Sigma-Aldrich; Cat\# MAK016). Liver lysates were made by homogenization following the manufacturer's instructions using a Tissue Lyser (Qiagen). Hepatic glycogen levels were normalized for protein concentrations determined by Bradford Reagent (Bio-Rad).

\section{Western blotting}

Liver specimens were homogenized in RIPA buffer in the presence of complete protease inhibitor cocktail (Sigma), incubated for $20 \mathrm{~min}$ at $4^{\circ} \mathrm{C}$ and centrifuged at $16,800 \mathrm{~g}$ for $10 \mathrm{~min}$. Pellets were discarded and cell lysates were used for western blots. Total protein concentration in cellular extracts was measured using the Bradford Reagent (Bio-Rad). Protein extracts were separated by SDS-PAGE and transferred onto polyvinylidene difluoride (PVDF) membranes. Blots were blocked with TBS-Tween-20 containing $5 \%$ non-fat milk for $1 \mathrm{~h}$ at room temperature followed by incubation with primary antibody overnight at $4^{\circ} \mathrm{C}$. The primary antibodies used were: rabbit anti-LC3B (Novus Biologicals; Cat\# NB-100-2220; dilution: 1/1,000), mouse anti-p62 (Abnova; Cat\# H00008878-M01; dilution: 1/1,000), mouse anti-NBR1 (Abnova; Cat\# H00004077-M01; dilution: 1/1,000), rabbit anti-PYGL (Proteintech; Cat\#15851-1-AP; dilution: 1/1,000), rabbit anti-NAGS (Abcam; Cat\# ab65536; dilution: 1/ 1,000), rabbit anti-CPS1 (Abcam; Cat\# ab45956; dilution: 1/1,000), rabbit anti-OTC (Novus Biologicals; Cat\# NBP1-31582; dilution: 1/1,000), mouse anti-ASS1 (Abcam; Cat\# ab124465; dilution: 1/1,000), rabbit anti-ASL (Abcam; Cat\# ab201026; dilution: 1/ 1,000), rabbit anti-ARG1 (Abcam; Cat\# ab91279; dilution: 1/1,000), mouse anti- $\beta$-actin (Novus Biologicals; Cat\# NB600-501; dilution: $1 /$ 3,000), and mouse anti-GAPDH (Santa Cruz Biotechnology; Cat\# sc32233; dilution: 1/3,000). Proteins of interest were detected with horseradish peroxidase (HRP)-conjugated goat anti-mouse or antirabbit IgG antibody (GE Healthcare). Peroxidase substrate was provided by ECL Western Blotting Substrate kit (Pierce). Densitometric analyses of the western blotting bands were performed using ImageJ Software (Fiji 2).

\section{Electron microscopy}

For EM analyses, liver specimens were fixed in $1 \%$ glutaraldehyde in 0.2 M HEPES buffer. Small blocks of liver tissues were then postfixed in $\mathrm{OsO}_{4}$ and uranyl acetate. 


\section{The paper explained}

Problem

Urea cycle disorders have high morbidity and mortality and require development of novel and more effective therapies. Ornithine transcarbamylase (OTC) and argininosuccinate lyase (ASL) deficiencies are the two most common urea cycle disorders.

\section{Results}

Mice carrying a Beclin-1 activating mutation have increased ammonia detoxification and treatment with the cell-penetrating autophagyinducing Tat-Beclin-1 peptide improved phenotypic and biochemical abnormalities of mouse models of OTC and ASL deficiencies.

Impact

Drugs activating Beclin-1 have potential for therapy of UCD.

After dehydration through a graded series of ethanol solutions and propylene oxide tissue samples were embedded in epoxy resin and polymerized at $60^{\circ} \mathrm{C}$ for $72 \mathrm{~h}$. From each sample, thin sections were cut with a Leica EM UC7 ultramicrotome and images acquired by FEI Tecnai - 12 (FEI, Einhoven, The Netherlands) EM equipped with Veletta CCD camera for digital image acquisition.

\section{Statistical analyses}

Data were analysed using GraphPad Prism 5.0 software, San Diego, CA, USA. Comparisons of continuous variables between two and more experimental groups were performed using the two-tailed unpaired Student's $t$-test or one-way ANOVA with Tukey's or Dunnett's post hoc tests. Two-way ANOVA and Tukey's post hoc tests were performed to compare two groups relative to two factors. Kaplan-Meier survival curves were compared with the log-rank test. No statistical methods were used to predetermine the sample size. A minimum of $n=5$ per group was included, and the sample size was increased if needed to achieve statistical significance. No formal randomization procedure was used but assignment of mice to treatment groups was based on mouse identification numbers, and the investigators were not blinded. Number of replicates is reported in the figure legends. Data are expressed as means \pm SEM. $P$ values $<0.05$ were considered statistically significant.

\section{Data availability}

This study includes no data deposited in external repositories. All data reported in the paper are included in the manuscript or available in the Appendix.

Expanded View for this article is available online.

\section{Acknowledgements}

We thank Edoardo Nusco and Carmen Lanzara (TIGEM) for technical assistance with mouse studies. This work was supported by grants of Fondazione Telethon Italy (to N.B.-P.), MIUR (PRIN2017 to N.B.-P.), NIHR Great Ormond Street Hospital Biomedical Research Centre (to J.B. and S.E.), Nutricia Metabolic
Research Grant (to J.B.), London Advanced Therapy/Confidence in Collaboration award 2CiC017 (to J.B.), Medical Research Council, Grant/Award Number: MR/ T008024/1 (to J.B.) and Innovate UK Biomedical Catalyst Early stage award 14720 (to J.B.). The views expressed are those of the author(s) and not necessarily those of the NHS, the NIHR or the Department of Health.

\section{Author contributions}

LRS performed study concept and design, acquisition of data, analysis, interpretation of data and wrote the manuscript; SC performed ASL activity assay and argininosuccinate determinations; GDS performed studies in spf-ash mice; DPP performed studies in As/ ${ }^{\mathrm{Neo} / \mathrm{Neo}}$ mice; ADA performed some Western blots; GB performed studies on BecnI ${ }^{F 121 A}$ mice; EP performed EM; DP analysed ${ }^{1} \mathrm{H}$-NMR data; PC performed ${ }^{1} \mathrm{H}$-NMR; AM supervised ${ }^{1} \mathrm{H}$-NMR studies; YK and PBM performed ${ }^{15} \mathrm{~N}$-argininosuccinate determinations, $\mathrm{MO}$, SE and SNW participated to studies in As/ ${ }^{\text {Neo/Neo }}$ mice; CS supervised studies on BecnI ${ }^{F 121 A}$ mice; AFM supervised studies in spf-ash mice; JB supervised studies in $A$ I $^{\text {Neo/Neo }}$ mice; NB-P supervised the study, performed study concept and design, analysis and interpretation of data, and wrote the manuscript.

\section{Conflict of interest}

The authors declare no that they have no conflict of interests.

\section{References}

Allaire M, Rautou PE, Codogno P, Lotersztajn S (2019) Autophagy in liver diseases: time for translation? J Hepatol 70: 985-998

Ashe KM, Taylor KM, Chu Q, Meyers E, Ellis A, Jingozyan V, Klinger K, Finn PF, Cooper CG, Chuang WL et al (2010) Inhibition of glycogen biosynthesis via mTORC1 suppression as an adjunct therapy for Pompe disease. Mol Genet Metab 100: 309-315

Ashley SN, Nordin JML, Buza EL, Greig JA, Wilson JM (2018) Adeno-associated viral gene therapy corrects a mouse model of argininosuccinic aciduria. Mol Genet Metab 125: $241-250$

Badizadegan K, Perez-Atayde AR (1997) Focal glycogenosis of the liver in disorders of ureagenesis: its occurrence and diagnostic significance. Hepatology 26: 365-373

Bartolomeo R, Cinque L, De Leonibus C, Forrester A, Salzano AC, Monfregola J, De Gennaro E, Nusco E, Azario I, Lanzara C et al (2017) mTORC1 hyperactivation arrests bone growth in lysosomal storage disorders by suppressing autophagy. J Clin Invest 127: 3717-3729

Baruteau J, Jameson E, Morris AA, Chakrapani A, Santra S, Vijay S, Kocadag H, Beesley CE, Grunewald S, Murphy E et al (2017) Expanding the phenotype in argininosuccinic aciduria: need for new therapies. J Inherit Metab Dis 40: $357-368$

Baruteau J, Perocheau DP, Hanley J, Lorvellec M, Rocha-Ferreira E, Karda R, $\mathrm{Ng}$ J, Suff N, Diaz JA, Rahim AA et al (2018) Argininosuccinic aciduria fosters neuronal nitrosative stress reversed by Asl gene transfer. Nat Commun 9: 3505

Baruteau J, Diez-Fernandez C, Lerner S, Ranucci G, Gissen P, Dionisi-Vici C, Nagamani S, Erez A, Haberle J (2019a) Argininosuccinic aciduria: recent pathophysiological insights and therapeutic prospects. J Inherit Metab Dis 42: $1147-1161$

Baruteau J, Khalil Y, Grunewald S, Zancolli M, Chakrapani A, Cleary M, Davison J, Footitt E, Waddington SN, Gissen P et al (2019b) Urea cycle related amino acids measured in dried bloodspots enable long-term in vivo monitoring and therapeutic adjustment. Metabolites 9: 275. 
Bigot A, Tchan MC, Thoreau B, Blasco H, Maillot F (2017) Liver involvement in urea cycle disorders: a review of the literature. J Inherit Metab Dis 40: $757-769$

Burrage LC, Madan S, Li X, Ali S, Mohammad M, Stroup BM, Jiang MM, Cela $\mathrm{R}$, Bertin T, Jin Z et al (2020) Chronic liver disease and impaired hepatic glycogen metabolism in argininosuccinate lyase deficiency. JCI Insight 5: e132342

Castellana M, Wilson MZ, Xu Y, Joshi P, Cristea IM, Rabinowitz JD, Citai Z, Wingreen NS (2014) Enzyme clustering accelerates processing of intermediates through metabolic channeling. Nat Biotechnol 32: 1011-1018

Cheung CW, Cohen NS, Raijman L (1989) Channeling of urea cycle intermediates in situ in permeabilized hepatocytes. J Biol Chem 264: $4038-4044$

Chiang WC, Wei Y, Kuo YC, Wei S, Zhou A, Zou Z, Yehl J, Ranaghan MJ, Skepner A, Bittker JA et al (2018) High-throughput screens to identify autophagy inducers that function by disrupting Beclin $1 / \mathrm{BCl}-2$ binding. ACS Chem Biol 13: 2247-2260

Cinque L, Forrester A, Bartolomeo R, Svelto M, Venditti R, Montefusco S, Polishchuk E, Nusco E, Rossi A, Medina DL et al (2015) FGF signalling regulates bone growth through autophagy. Nature 528: 272-275

Cohen NS, Cheung CW, Sijuwade E, Raijman L (1992) Kinetic properties of carbamoyl-phosphate synthase (ammonia) and ornithine carbamoyltransferase in permeabilized mitochondria. Biochem / 282(Pt 1): $173-180$

Cunningham SC, Spinoulas A, Carpenter KH, Wilcken B, Kuchel PW, Alexander IE (2009) AAV2/8-mediated correction of OTC deficiency is robust in adult but not neonatal Spf(ash) mice. Mol Ther 17: 1340-1346

Enns GM, Berry SA, Berry GT, Rhead WJ, Brusilow SW, Hamosh A (2007) Survival after treatment with phenylacetate and benzoate for urea-cycle disorders. N Engl J Med 356: 2282-2292

Erez A, Nagamani SC, Shchelochkov OA, Premkumar MH, Campeau PM, Chen Y, Garg HK, Li L, Mian A, Bertin TK et al (2011) Requirement of argininosuccinate lyase for systemic nitric oxide production. Nat Med 17 1619-1626

Farah BL, Landau DJ, Sinha RA, Brooks ED, Wu Y, Fung SYS, Tanaka T, Hirayama M, Bay BH, Koeberl DD et al (2016) Induction of autophagy improves hepatic lipid metabolism in glucose-6-phosphatase deficiency. J Hepatol 64: $370-379$

Fernandez AF, Sebti S, Wei Y, Zou Z, Shi M, McMillan KL, He C, Ting T, Liu Y, Chiang WC et al (2018) Disruption of the beclin 1-BCL2 autophagy regulatory complex promotes longevity in mice. Nature 558: 136-140

Haberle J, Burlina A, Chakrapani A, Dixon M, Karall D, Lindner M, Mandel H, Martinelli D, Pintos-Morell G, Santer R et al (2019) Suggested guidelines for the diagnosis and management of urea cycle disorders: first revision. J Inherit Metab Dis 42: 1192-1230

Hazari Y, Bravo-San Pedro JM, Hetz C, Galluzzi L, Kroemer G (2020) Autophagy in hepatic adaptation to stress. J Hepatol 72: 183-196

He M, Ding Y, Chu C, Tang J, Xiao Q, Luo ZC (2016) Autophagy induction stabilizes microtubules and promotes axon regeneration after spinal cord injury. Proc Natl Acad Sci USA 113: 11324-11329

Hill SM, Wrobel L, Rubinsztein DC (2019) Post-translational modifications of Beclin 1 provide multiple strategies for autophagy regulation. Cell Death Differ 26: 617-629

Hodges PE, Rosenberg LE (1989) The spfash mouse: a missense mutation in the ornithine transcarbamylase gene also causes aberrant mRNA splicing. Proc Natl Acad Sci USA 86: $4142-4146$

Hosel M, Huber A, Bohlen S, Lucifora J, Ronzitti G, Puzzo F, Boisgerault F, Hacker UT, Kwanten WJ, Kloting N et al (2017) Autophagy determines efficiency of liver-directed gene therapy with adeno-associated viral vectors. Hepatology 66: 252-265

Karsli-Uzunbas G, Guo JY, Price S, Teng X, Laddha SV, Khor S, Kalaany NY, Jacks T, Chan CS, Rabinowitz JD et al (2014) Autophagy is required for glucose homeostasis and lung tumor maintenance. Cancer Discou 4: 914-927

Kaur J, Debnath J (2015) Autophagy at the crossroads of catabolism and anabolism. Nat Reu Mol Cell Biol 16: 461-472

Kho J, Tian X, Wong WT, Bertin T, Jiang MM, Chen S, Jin Z, Shchelochkov OA, Burrage LC, Reddy AK et al (2018) Argininosuccinate lyase deficiency causes an endothelial-dependent form of hypertension. Am J Hum Genet 103: $276-287$

Koo M, Lipshutz GS, Cederbaum SD, Lassman C (2017) Biopsy-proven hepatocellular carcinoma in a 53-year-old woman with arginase deficiency. Pediatr Deu Pathol 20: 517-521

Kurtz CB, Millet YA, Puurunen MK, Perreault M, Charbonneau MR, Isabella VM, Kotula JW, Antipov E, Dagon Y, Denney WS et al (2019) An engineered E. coli Nissle improves hyperammonemia and survival in mice and shows dose-dependent exposure in healthy humans. Sci Transl Med 11: eaau7975

Li J, Kim SG, Blenis J (2014) Rapamycin: one drug, many effects. Cell Metab 19: $373-379$

Liang C, Lee JS, Inn KS, Gack MU, Li Q, Roberts EA, Vergne I, Deretic V, Feng P, Akazawa $C$ et al (2008) Beclin1-binding UVRAC targets the class C Vps complex to coordinate autophagosome maturation and endocytic trafficking. Nat Cell Biol 10: 776-787

Martina JA, Diab HI, Lishu L, Jeong AL, Patange S, Raben N, Puertollano R (2014) The nutrient-responsive transcription factor TFE3 promotes autophagy, lysosomal biogenesis, and clearance of cellular debris. Sci Signal 7: ra9

Mori T, Nagai K, Mori M, Nagao M, Imamura M, lijima M, Kobayashi K (2002) Progressive liver fibrosis in late-onset argininosuccinate lyase deficiency. Pediatr Deu Pathol 5: 597-601

Moscioni D, Morizono H, McCarter RJ, Stern A, Cabrera-Luque J, Hoang A, Sanmiguel J, Wu D, Bell P, Gao GP et al (2006) Long-term correction of ammonia metabolism and prolonged survival in ornithine transcarbamylase-deficient mice following liver-directed treatment with adeno-associated viral vectors. Mol Ther 14: 25-33

Nagamani SC, Campeau PM, Shchelochkov OA, Premkumar MH, Guse K, Brunetti-Pierri N, Chen Y, Sun Q, Tang Y, Palmer D et al (2012) Nitricoxide supplementation for treatment of long-term complications in argininosuccinic aciduria. Am J Hum Genet 90: 836-846

Pareek V, Tian H, Winograd N, Benkovic SJ (2020) Metabolomics and mass spectrometry imaging reveal channeled de novo purine synthesis in cells. Science 368: 283-290

Peraro L, Zou Z, Makwana KM, Cummings AE, Ball HL, Yu H, Lin YS, Levine B, Kritzer JA (2017) Diversity-oriented stapling yields intrinsically cellpenetrant inducers of autophagy. J Am Chem Soc 139: 7792-7802

Pietrocola F, Pol J, Vacchelli E, Rao S, Enot DP, Baracco EE, Levesque S, Castoldi $\mathrm{F}$, Jacquelot N, Yamazaki T et al (2016) Caloric restriction mimetics enhance anticancer immunosurveillance. Cancer Cell 30: 147-160

Prats C, Graham TE, Shearer J (2018) The dynamic life of the glycogen granule. J Biol Chem 293: 7089-7098

Prieve MG, Harvie P, Monahan SD, Roy D, Li AG, Blevins TL, Paschal AE, Waldheim M, Bell EC, Galperin A et al (2018) Targeted mRNA therapy for ornithine transcarbamylase deficiency. Mol Ther 26: 801-813

Prinsen H, Schiebergen-Bronkhorst BGM, Roeleveld MW, Jans JJM, de Sainvan der Velden MGM, Visser G, van Hasselt PM, Verhoeven-Duif NM (2016) Rapid quantification of underivatized amino acids in plasma by 
hydrophilic interaction liquid chromatography (HILIC) coupled with tandem mass-spectrometry. J Inherit Metab Dis 39: 651-660

Ranucci G, Rigoldi M, Cotugno G, Bernabei SM, Liguori A, Gasperini S, Goffredo BM, Martinelli D, Monti L, Francalanci P et al (2019) Chronic liver involvement in urea cycle disorders. J Inherit Metab Dis 42: 1118-1127

Rocchi A, Yamamoto S, Ting T, Fan Y, Sadleir K, Wang Y, Zhang W, Huang S, Levine B, Vassar R et al (2017) A Becn1 mutation mediates hyperactive autophagic sequestration of amyloid oligomers and improved cognition in Alzheimer's disease. PLoS Genet 13: e1006962

Shoji-Kawata S, Sumpter R, Leveno M, Campbell GR, Zou Z, Kinch L, Wilkins AD, Sun Q, Pallauf K, MacDuff D et al (2013) Identification of a candidate therapeutic autophagy-inducing peptide. Nature 494: 201-206

Song X, Zhu S, Chen P, Hou W, Wen Q, Liu J, Xie Y, Liu J, Klionsky DJ, Kroemer C et al (2018) AMPK-Mediated BECN1 phosphorylation promotes ferroptosis by directly blocking system Xc(-) activity. Curr Biol 28: 2388-2399.e5

Soria LR, Allegri G, Melck D, Pastore N, Annunziata P, Paris D, Polishchuk E, Nusco E, Thony B, Motta A et al (2018) Enhancement of hepatic autophagy increases ureagenesis and protects against hyperammonemia. Proc Natl Acad Sci USA 115: $391-396$

Soria LR, Brunetti-Pierri N (2018) Targeting autophagy for therapy of hyperammonemia. Autophagy 14: 1273-1275

Soria LR, Ah Mew N, Brunetti-Pierri N (2019) Progress and challenges in development of new therapies for urea cycle disorders. Hum Mol Genet 28 R42-R48

Soria LR, Brunetti-Pierri N (2019) Ammonia and autophagy: an emerging relationship with implications for disorders with hyperammonemia. J Inherit Metab Dis 42: 1097-1104

Spampanato C, Feeney E, Li L, Cardone M, Lim JA, Annunziata F, Zare H, Polishchuk R, Puertollano R, Parenti $G$ et al (2013) Transcription factor EB (TFEB) is a new therapeutic target for Pompe disease. EMBO Mol Med 5 : $691-706$

Sun Y, Yao X, Zhang QJ, Zhu M, Liu ZP, Ci B, Xie Y, Carlson D, Rothermel BA, Sun $Y$ et al (2018) Beclin-1-dependent autophagy protects the heart during sepsis. Circulation 138: 2247-2262
Sun RC, Dukhande W, Zhou Z, Young LEA, Emanuelle S, Brainson CF, Gentry MS (2019) Nuclear glycogenolysis modulates histone acetylation in human non-small cell lung cancers. Cell Metab 30: 903-916.e7

Vega-Rubin-de-Celis S, Zou Z, Fernandez AF, Ci B, Kim M, Xiao G, Xie Y, Levine B (2018) Increased autophagy blocks HER2-mediated breast tumorigenesis. Proc Natl Acad Sci USA 115: 4176-4181

Wang L, Bell P, Morizono H, He Z, Pumbo E, Yu H, White J, Batshaw ML, Wilson JM (2017) AAV gene therapy corrects OTC deficiency and prevents liver fibrosis in aged OTC-knock out heterozygous mice. Mol Cenet Metab 120: $299-305$

Wang L, Wang L, Zhu S, Zhang M, Dong Y, Wang FS (2019) A 6-year-old child with citrin deficiency and advanced hepatocellular carcinoma. Pediatrics 143: e20181931

Wilson JM, Shchelochkov OA, Gallagher RC, Batshaw ML (2012) Hepatocellular carcinoma in a research subject with ornithine transcarbamylase deficiency. Mol Genet Metab 105: 263-265

Yamamoto S, Kuramoto K, Wang N, Situ X, Priyadarshini M, Zhang W, Cordoba-Chacon J, Layden BT, He C (2018) Autophagy differentially regulates insulin production and insulin sensitivity. Cell Rep 23: 3286-3299

Yang Y, Wang L, Bell P, McMenamin D, He Z, White J, Yu H, Xu C, Morizono $\mathrm{H}$, Musunuru $\mathrm{K}$ et al (2016) A dual AAV system enables the Cas9-mediated correction of a metabolic liver disease in newborn mice. Nat Biotechnol 34: $334-338$

Yaplito-Lee J, Chow CW, Boneh A (2013) Histopathological findings in livers of patients with urea cycle disorders. Mol Genet Metab 108: 161-165

Ye X, Robinson MB, Batshaw ML, Furth EE, Smith I, Wilson JM (1996) Prolonged metabolic correction in adult ornithine transcarbamylasedeficient mice with adenoviral vectors. J Biol Chem 271: 3639-3646

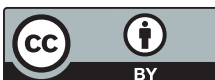

License: This is an open access article under the terms of the Creative Commons Attribution License, which permits use, distribution and reproduction in any medium, provided the original work is properly cited. 